4

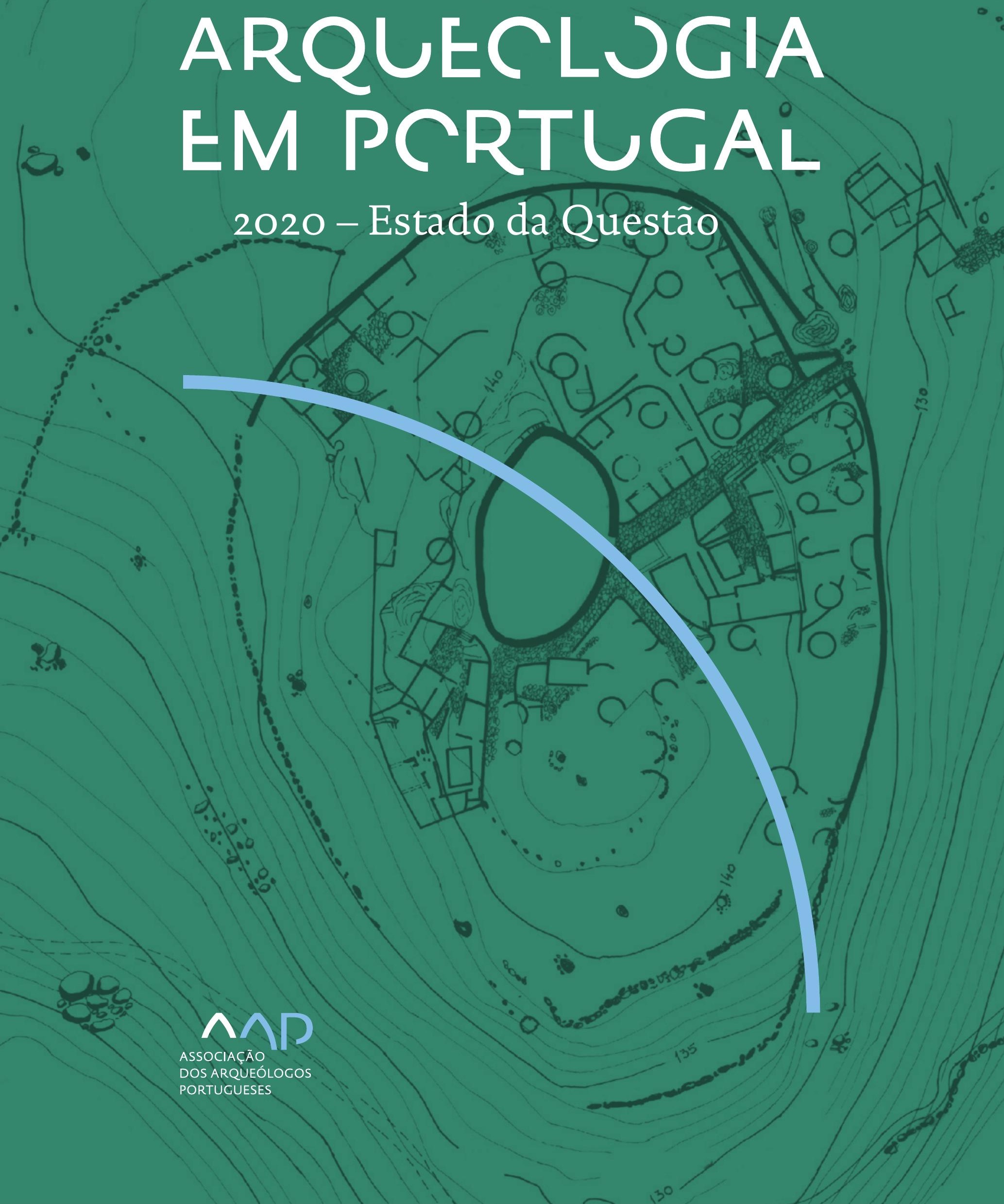


Coordenação editorial: José Morais Arnaud, César Neves e Andrea Martins Design gráfico: Flatland Design

AAP - ISBN: 978-972-9451-89-8

CITCEM - ISBN: 978-989-8970-25-1

Associação dos Arqueólogos Portugueses e CITCEM

Lisboa, 2020

O conteúdo dos artigos é da inteira responsabilidade dos autores. Sendo assim a Associação dos Arqueólogos Portugueses declina qualquer responsabilidade por eventuais equívocos ou questões de ordem ética e legal.

Desenho de capa:

Planta do castro de Monte Mozinho (Museu Municipal de Penafiel).

\section{$\hat{\wedge} \mathrm{P}$}

DOS ARQUEÓLOGOS PORTUGUESES

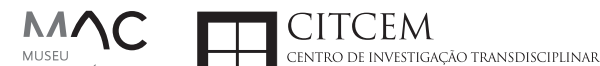
MUSEU
ARQUELLÓGICO
DO CARMO
U.PORTO

FLUP FACULDADE DE LETRAS
UNIVERSIDADE DO PORTO

Apoio

EC para a Ciência 


\section{Índice}

15 Prefácio

José Morais Arnaud

\section{Historiografia e Teoria}

17 Território, comunidade, memória e emoção: a contribuição da história da arqueologia (algumas primeiras e breves reflexões)

Ana Cristina Martins

25 Como descolonizar a arqueologia portuguesa?

Rui Gomes Coelho

41 Arqueologia e Modernidade: uma revisitação pessoal e breve de alguns aspetos da obra homónima de Julian Thomas de 2004

Vítor Oliveira Jorge

57 Dados para a História das Mulheres na Arqueologia portuguesa, dos finais do século XIX aos inícios do século XX: números, nomes e tabelas

Filipa Dimas / Mariana Diniz

73 Retractos da arqueologia portuguesa na imprensa: (in)visibilidades no feminino

Catarina Costeira / Elsa Luís

85 Arqueologia e Arqueólogos no Norte de Portugal Jacinta Bugalhão

101 Vieira Guimarães (1864-1939) e a arqueologia em Tomar: uma abordagem sobre o território e as gentes

João Amendoeira Peixoto / Ana Cristina Martins

115 Os memoráveis? A arqueologia algarvia na imprensa nacional e regional na presente centúria (2001-2019): características, visões do(s) passado(s) e a arqueologia

enquanto marca

Frederico Agosto / João Silva

129 A Evolução da Arqueologia Urbana e a Valorização Patrimonial no Barlavento Algarvio: Os casos de Portimão e Silves

Artur Mateus / Diogo Varandas / Rafael Boavida

\section{Gestão, Valorização e Salvaguarda do Património}

145 O Caderno Reivindicativo e as condições de trabalho em Arqueologia Miguel Rocha / Liliana Matias Carvalho / Regis Barbosa / Mauro Correia / Sara Simões / Jacinta Bugalhão / Sara Brito / Liliana Veríssimo Carvalho / Richard Peace / Pedro Peça / Cézer Santos

155 Os Estudos de Impacte Patrimonial como elemento para uma estratégia sustentável de minimização de impactes no âmbito de reconversões agrícolas Tiago do Pereiro

165 Salvaguarda de Património arqueológico em operações florestais: gestão e sensibilização Filipa Bragança / Gertrudes Zambujo / Sandra Lourenço / Belém Paiva / Carlos Banha / Frederico Tatá Regala / Helena Moura / Jacinta Bugalhão / João Marques / José Correia / Pedro Faria / Samuel Melro

179 Os valores do Património: uma investigação sobre os Sítios Pré-históricos de Arte Rupestre do Vale do Rio Côa e de Siega Verde José Paulo Francisco 
189 Conjugando recursos arqueológicos e naturais para potenciar as visitas ao Geoparque Litoral de Viana do Castelo (Noroeste de Portugal)

Hugo A. Sampaio / Ana M.S. Bettencourt / Susana Marinho / Ricardo Carvalhido

203 Áreas de Potencial Arqueológico na Região do Médio Tejo: Modelo Espacial Preditivo Rita Ferreira Anastácio / Ana Filipa Martins / Luiz Oosterbeek

223 Património Arqueológico e Gestão Territorial: O contributo da Arqueologia para a revisão do PDM de Avis

Ana Cristina Ribeiro

237 A coleção arqueológica do extinto Museu Municipal do Porto - Origens, Percursos e Estudos

Sónia Couto

251 Valpaços - uma nova carta arqueológica

Pedro Pereira / Maria de Fátima Casares Machado

263 Arqueologia na Cidade de Peniche

Adriano Constantino / Luís Rendeiro

273 Arqueologia Urbana: a cidade de Lagos como caso de Estudo Cátia Neto

285 Estratégias de promoção do património cultural subaquático nos Açores. O caso da ilha do Faial

José Luís Neto / José Bettencourt / Luís Borges / Pedro Parreira

297 Carta Arqueológica da Cidade Velha: Uma primeira abordagem

Jaylson Monteiro / Nireide Tavares / Sara da Veiga / Claudino Ramos / Edson Brito /

Carlos Carvalho / Francisco Moreira / Adalberto Tavares

311 Antropologia Virtual: novas metodologias para a análise morfológica e funcional Ricardo Miguel Godinho / Célia Gonçalves

\section{Didáctica da Arqueologia}

327 Como os projetos de Arqueologia podem contribuir para uma comunidade culturalmente mais consciente Alexandra Figueiredo / Claúdio Monteiro / Adolfo Silveira / Ricardo Lopes

337 Educação Patrimonial - Um cidadão esclarecido é um cidadão ativo! Ana Paula Almeida

351 A aproximação da Arqueologia à sala de aula: um caso de estudo no $3^{\circ}$ ciclo do Ensino Básico Luís Serrão Gil

363 Arqueologia 3.o - Pensar e comunicar a Arqueologia para um futuro sustentável Mónica Rolo

377 “Conversa de Arqueólogos" - Divulgar a Arqueologia em tempos de Pandemia Diogo Teixeira Dias

389 Escola Profissional de Arqueologia: desafios e oportunidades Susana Nunes / Dulcineia Pinto / Júlia Silva / Ana Mascarenhas

399 Os Museus de Arqueologia e os Jovens: a oferta educativa para o público adolescente Beatriz Correia Barata / Leonor Medeiros

411 O museu universitário como mediador entre a ciência e a sociedade: o exemplo da secção de arqueologia no Museu de História Natural e da Ciência da Universidade do Porto (MHNC-UP)

Rita Gaspar 
421 Museu de Lanifícios: Real Fábrica de Panos. Atividades no âmbito da Arqueologia Beatriz Correia Barata / Rita Salvado

427 Arqueologia Pública e o caso da localidade da Mata (Torres Novas) Cláudia Manso / Ana Rita Ferreira / Cristiana Ferreira / Vanessa Cardoso Antunes

431 Do sítio arqueológico ao museu: um percurso (também) didático Lídia Fernandes

447 Estão todos convidados para a Festa! E para dançar também... O projecto do Serviço Educativo do Museu Arqueológico do Carmo na $5^{\underline{a}}$ Edição da Festa da Arqueologia Rita Pires dos Santos

459 O “Clã de Carenque”, um projeto didático de arqueologia Eduardo Gonzalez Rocha

469 Mediação cultural: peixe que puxa carroça nas Ruínas Romanas de Troia Inês Vaz Pinto / Ana Patrícia Magalhães / Patrícia Brum / Filipa Santos

481 Didática Arqueológica, experiências do Projeto Mértola Vila Museu Maria de Fátima Palma / Clara Rodrigues / Susana Gómez / Lígia Rafael

\section{Arte Rupestre}

497 Os inventários de arte rupestre em Portugal Mila Simões de Abreu

513 O projeto FIRST-ART - conservação, documentação e gestão das primeiras manifestações de arte rupestre no Sudoeste da Península Ibérica: as grutas do Escoural e Maltravieso Sara Garcês / Hipólito Collado / José Julio García Arranz / Luiz Oosterbeek / António Carlos Silva / Pierluigi Rosina / Hugo Gomes / Anabela Borralheiro Pereira / George Nash / Esmeralda Gomes / Nelson Almeida / Carlos Carpetudo

523 Trabalhos de documentação de arte paleolítica realizados no âmbito do projeto PalæoCôa André Tomás Santos / António Fernando Barbosa / Luís Luís / Marcelo Silvestre / Thierry Aubry

537 Imagens fantasmagóricas, silhuetas elusivas: as figuras humanas na arte do Paleolítico Superior da região do Côa Mário Reis

$55^{1}$ Os motivos zoomórficos representados nas placas de tear de Vila Nova de São Pedro (Azambuja, Portugal) Andrea Martins / César Neves / José M. Arnaud / Mariana Diniz

571 Arte Rupestre do Monte de Góios (Lanhelas, Caminha). Síntese dos resultados dos trabalhos efectuados em 2007-2009 Mário Varela Gomes

599 Gravuras rupestres de barquiformes no Monte de S. Romão, Guimarães, Noroeste de Portugal Daniela Cardoso

613 Círculos segmentados gravados na Bacia do Rio Lima (Noroeste de Portugal): contributos para o seu estudo Diogo Marinho / Ana M.S. Bettencourt / Hugo Aluai Sampaio

631 Equídeos gravados no curso inferior do Rio Mouro, Monção (NW Portugal). Análise preliminar Coutinho, L.M. / Bettencourt, A.M.S / Sampaio, Hugo A.S

645 Paletas na Arte Rupestre do Noroeste de Portugal. Inventário preliminar Bruna Sousa Afonso / Ana M. S. Bettencourt / Hugo A. Sampaio 


\section{Pré-História}

661 O projeto Miño/Minho: balanço de quatro anos de trabalhos arqueológicos Sérgio Monteiro-Rodrigues / João Pedro Cunha-Ribeiro / Eduardo Méndez-Quintas / Carlos Ferreira / Pedro Xavier / José Meireles / Alberto Gomes / Manuel Santonja / Alfredo Pérez-González

677 A ocupação paleolítica da margem esquerda do Baixo Minho: a indústria lítica do sítio de Pedreiras 2 (Monção, Portugal) e a sua integração no contexto regional Carlos Ferreira / João Pedro Cunha-Ribeiro / Sérgio Monteiro-Rodrigues / Eduardo Méndez-Quintas / Pedro Xavier / José Meireles / Alberto Gomes / Manuel Santonja / Alfredo Pérez-González

693 O sítio acheulense do Plistocénico médio da Gruta da Aroeira Joan Daura / Montserrat Sanz / Filipa Rodrigues / Pedro Souto / João Zilhão

703 As sociedades neandertais no Barlavento algarvio: modelos preditivos com recurso aos SIG

Daniela Maio

715 A utilização de quartzo durante o Paleolítico Superior no território dos vales dos rios Vouga e Côa

Cristina Gameiro / Thierry Aubry / Bárbara Costa / Sérgio Gomes / Luís Luís / Carmen Manzano / André Tomás Santos

733 Uma perspetiva diacrónica da ocupação do concheiro do Cabeço da Amoreira (Muge, Portugal) a partir da tecnologia lítica Joana Belmiro / João Cascalheira / Célia Gonçalves

745 Novos dados sobre a Pré-história Antiga no concelho de Palmela. A intervenção arqueológica no sítio do Poceirão I

Michelle Teixeira Santos

757 Problemas em torno de Datas Absolutas Pré-Históricas no Norte do Alentejo Jorge de Oliveira

771 Povoamento pré-histórico nas áreas montanhosas do NO de Portugal: o Abrigo 1 de Vale de Cerdeira Pedro Xavier / José Meireles / Carlos Alves

783 Apreciação do povoamento do Neolítico Inicial na Baixa Bacia do Douro. A Lavra I (Serra da Aboboreira) como caso de estudo Maria de Jesus Sanches

797 O Processo de Neolitização na Plataforma do Mondego: os dados do Sector C do Outeiro dos Castelos de Beijós (Carregal do Sal)

João Carlos de Senna-Martinez / José Manuel Quintã Ventura / Andreia Carvalho / Cíntia Maurício

823 Novos trabalhos na Lapa da Bugalheira (Almonda, Torres Novas) Filipa Rodrigues / Pedro Souto / Artur Ferreira / Alexandre Varanda / Luís Gomes / Helena Gomes / João Zilhão

837 A pedra polida e afeiçoada do sítio do Neolítico médio da Moita do Ourives (Benavente, Portugal)

César Neves

857 Casal do Outeiro (Encarnação, Mafra): novos contributos para o conhecimento do povoamento do Neolítico final na Península de Lisboa.

Cátia Delicado / Carlos Maneira e Costa / Marta Miranda / Ana Catarina Sousa

873 Stresse infantil, morbilidade e mortalidade no sítio arqueológico do Neolítico Final/ Calcolítico ( $4^{\circ}$ e $3^{\circ}$ milénio a.C.) do Monte do Carrascal 2 (Ferreira do Alentejo, Beja) Liliana Matias de Carvalho / Sofia N. Wasterlain 
885 Come together: O Conjunto Megalítico das Motas (Monção, Viana do Castelo) e as expressões Campaniformes do Alto Minho Ana Catarina Basílio / Rui Ramos

899 Trabalhos arqueológicos no sítio Calcolítico da Pedreira do Poio Carla Magalhães / João Muralha / Mário Reis / António Batarda Fernandes

913 O sítio arqueológico de Castanheiro do Vento. Da arquitectura do sítio à arquitectura de um território João Muralha Cardoso

925 Estudo zooarqueológico das faunas do Calcolítico final de Vila Nova de São Pedro (Azambuja, Portugal): Campanhas de 2017 e 2018 Cleia Detry / Ana Catarina Francisco / Mariana Diniz / Andrea Martins / César Neves / José Morais Arnaud

943 As faunas depositadas no Museu Arqueológico do Carmo provenientes de Vila Nova de São Pedro (Azambuja): as campanhas de 1937 a 1967 Ana Catarina Francisco / Cleia Detry / César Neves / Andrea Martins / Mariana Diniz / José Morais Arnaud

959 Análise funcional de material lítico em sílex do castro de Vila Nova de S. Pedro (Azambuja, Portugal): uma primeira abordagem Rafael Lima

971 O recinto da Folha do Ouro 1 (Serpa) no contexto dos recintos de fossos calcolíticos alentejanos

António Carlos Valera / Tiago do Pereiro / Pedro Valério / António M. Monge Soares

\section{Proto-História}

987 Produção de sal marinho na Idade do Bronze do noroeste Português. Alguns dados para uma reflexão

Ana M. S. Bettencourt / Sara Luz / Nuno Oliveira / Pedro P. Simões / Maria Isabel C. Alves / Emílio Abad-Vidal

1001 A estátua-menir do Pedrão ou de São Bartolomeu do Mar (Esposende, noroeste de Portugal) no contexto arqueológico da fachada costeira de entre os rios Neiva e Cávado Ana M. S. Bettencourt / Manuel Santos-Estévez / Pedro Pimenta Simões / Luís Gonçalves

1015 O Castro do Muro (Vandoma/Baltar, Paredes) - notas para uma biografia de ocupação da Idade do Bronze à Idade Média

Maria Antónia D. Silva / Ana M. S. Bettencourt / António Manuel S. P. Silva / Natália Félix

1031 Do Bronze Final à Idade Média - continuidades e hiatos na ocupação de Povoados em Oliveira de Azeméis João Tiago Tavares / Adriaan de Man

1041 As faunas do final da Idade do Bronze no Sul de Portugal: leituras desde o Outeiro do Circo (Beja)

Nelson J. Almeida / Íris Dias / Cleia Detry / Eduardo Porfírio / Miguel Serra

1055 A Espada do Monte das Oliveiras (Serpa) - uma arma do Bronze Pleno do Sudoeste Rui M. G. Monge Soares / Pedro Valério / Mariana Nabais / António M. Monge Soares

1065 São Julião da Branca (Albergaria-a-Velha) - Investigação e valorização de um povoado do Bronze Final

António Manuel S. P. Silva / Paulo A. P. Lemos / Sara Almeida e Silva / Edite Martins de Sá

1083 Do castro de S. João ao Mosteiro de Santa Clara: notícia de uma intervenção arqueológica, em Vila do Conde Rui Pinheiro 
1095 O castro de Ovil (Espinho), um quarto de século de investigação - resultados e questões em aberto

Jorge Fernando Salvador / António Manuel S. P. Silva

1111 O Castro de Salreu (Estarreja), um povoado proto-histórico no litoral do Entre Douro e Vouga

Sara Almeida e Silva / António Manuel S. P. Silva / Paulo A. P. Lemos / Edite Martins de Sá

1127 Castro de Nossa Senhora das Necessidades (Sernancelhe): uma primeira análise artefactual Telma Susana O. Ribeiro

${ }_{1141}$ A cividade de Bagunte. O estado atual da investigação Pedro Brochado de Almeida

1153 Zoomorfos na cerâmica da Idade do Ferro no NW Peninsular: inventário, cronologias e significado Nuno Oliveira / Cristina Seoane

1163 Vasos gregos em Portugal: diferentes maneiras de contar a história do intercâmbio cultural na Idade do Ferro

Daniela Ferreira

1175 Os exotica da necrópole da Idade do Ferro do Olival do Senhor dos Mártires (Alcácer do Sal) no seu contexto regional

Francisco B. Gomes

\section{Antiguidade Clássica e Tardia}

1191 O uso de madeira como combustível no sítio da Quinta de Crestelos (Baixo Sabor): da Idade do Ferro à Romanização Filipe Vaz / João Tereso / Sérgio Simões Pereira / José Sastre / Javier Larrazabal Galarza / Susana Cosme / José António Pereira / Israel Espi

1207 Cultivos de Época Romana no Baixo Sabor: continuidade em tempos de mudança? João Pedro Tereso / Sérgio Simões Pereira / Filipe Santos / Luís Seabra / Filipe Vaz

1221 A casa romana na Hispânia: aplicação dos modelos itálicos nas províncias ibéricas Fernanda Magalhães / Diego Machado / Manuela Martins

1235 As pinturas murais romanas da Rua General Sousa Machado, n. ${ }^{5}$ 1, Chaves José Carvalho

1243 Trás do Castelo (Vale de Mir, Pegarinhos, Alijó) - Uma exploração agrícola romana do Douro

Tony Silvino / Pedro Pereira

1255 A sequência de ocupação no quadrante sudeste de Bracara Augusta: as transformações de uma unidade doméstica Lara Fernandes / Manuela Martins

1263 Os Mosaicos com decoração geométrica e geométrico-vegetalista dos sítios arqueológicos da área do Conuentus Bracaraugustanus. Novas abordagens quanto à conservação, restauro, decoração e datação Maria de Fátima Abraços / Licínia Wrench

1277 “Casa Romana” do Castro de São Domingos (Cristelos, Lousada): Escavação, Estudo e Musealização Paulo André de P. Lemos

1291 A arqueobotânica no Castro de Guifões (Matosinhos, Noroeste de Portugal): O primeiro estudo carpológico

Luís Seabra / Andreia Arezes / Catarina Magalhães / José Varela / João Pedro Tereso 
1305 Um Horreum Augustano na Foz do Douro (Monte do Castelo de Gaia, Vila Nova de Gaia) Rui Ramos

1311 Ponderais romanos na Lusitânia: padrões, formas, materiais e contextos de utilização Diego Barrios Rodríguez

1323 Um almofariz centro-itálico na foz do Mondego

Marco Penajoia

1335 Estruturas romanas de Carnide - Lisboa Luísa Batalha / Mário Monteiro / Guilherme Cardoso

1347 O contexto funerário do sector da "necrópole NO" da Rua das Portas de S. Antão (Lisboa): o espaço, os artefactos, os indivíduos e a sua interconectividade na interpretação do passado Sílvia Loja, José Carlos Quaresma, Nelson Cabaço, Marina Lourenço, Sílvia Casimiro, Rodrigo Banha da Silva, Francisca Alves-Cardoso

${ }_{1361}$ Povoamento em época Romana na Amadora - resultados de um projeto pluridisciplinar Gisela Encarnação / Vanessa Dias

1371 A Arquitectura Residencial em Mirobriga (Santiago do Cacém): contributo a partir de um estudo de caso Filipe Sousa / Catarina Felício

${ }_{1385}$ O fim do ciclo. Saneamento e gestão de resíduos nos edifícios termais de Mirobriga (Santiago do Cacém)

Catarina Felício / Filipe Sousa

1399 Balsa, Topografia e Urbanismo de uma Cidade Portuária Vítor Silva Dias / João Pedro Bernardes / Celso Candeias / Cristina Tété Garcia

1413 No Largo das Mouras Velhas em Faro (2017): novas evidências da necrópole norte de Ossonoba e da sua ocupação medieval Ricardo Costeira da Silva / Paulo Botelho / Fernando Santos / Liliana Nunes

1429 Instrumentos de pesca recuperados numa fábrica de salga em Ossonoba (Faro) Inês Rasteiro / Ricardo Costeira da Silva / Paulo Botelho

1439 A Necrópole Romana do Eirô, Duas Igrejas (Penafiel): intervenção arqueológica de 2016 Laura Sousa / Teresa Soeiro

1457 Ritual, descarte ou afetividade? A presença de Canis lupus familiaris na Necrópole Noroeste de Olisipo (Lisboa)

Beatriz Calapez Santos / Sofia Simões Pereira / Rodrigo Banha da Silva / Sílvia Casimiro / Cleia Detry / Francisca Alves Cardoso

1467 Dinâmicas económicas em Bracara na Antiguidade Tardia Diego Machado / Manuela Martins / Fernanda Magalhães / Natália Botica

1479 Cerâmicas e Vidros da Antiguidade Tardia do Edifício sob a Igreja do Bom Jesus (Vila Nova de Gaia) Joaquim Filipe Ramos

1493 Novos contributos para a topografia histórica de Mértola no período romano e na Antiguidade Tardia Virgílio Lopes

\section{8. Época Medieval}

1511 Cerâmicas islâmicas no Garb setentrional "português": algumas evidências e incógnitas Constança dos Santos / Helena Catarino / Susana Gómez / Maria José Gonçalves / Isabel Inácio / Gonçalo Lopes / Jacinta Bugalhão / Sandra Cavaco / Jaquelina Covaneiro / Isabel Cristina Fernandes / Ana Sofia Gomes 
1525 Contributo para o conhecimento da cosmética islâmica, em Silves, durante a Idade Média Rosa Varela Gomes

1537 Yábura e o seu território - uma análise histórico-arqueológica de Évora entre os séculos VIII-XII José Rui Santos

1547 A encosta sul do Castelo de Palmela - resultados preliminares da escavação arqueológica Luís Filipe Pereira / Michelle Teixeira Santos

1559 A igreja de São Lourenço (Mouraria, Lisboa): um conjunto de silos e de cerâmica medieval islâmica

Andreia Filipa Moreira Rodrigues

1571 O registo material de movimentações populacionais no Médio Tejo, durante os séculos XII-XIII. Dois casos de "sunken featured buildings", nos concelhos de Cartaxo e Torres Novas Marco Liberato / Helena Santos / Nuno Santos

1585 O nordeste transmontano nos alvores da Idade média. Notas para reflexão Ana Maria da Costa Oliveira

1601 Sepulturas escavadas na rocha do Norte de Portugal e do Vale do Douro: primeiros resultados do Projecto SER-NPVD

Mário Jorge Barroca / César Guedes / Andreia Arezes / Ana Maria Oliveira

1619 "Portucalem Castrum Novum" entre o Mediterrâneo e o Atlântico: o estudo dos materiais cerâmicos alto-medievais do arqueossítio da rua de D. Hugo, nํ. 5 (Porto) João Luís Veloso

1627 A Alta Idade Média na fronteira de Lafões: notas preliminares sobre a Arqueologia no Concelho de Vouzela

Manuel Luís Real / Catarina Tente

1641 Um conjunto cerâmico medieval fora de portas: um breve testemunho aveirense Susana Temudo

${ }_{1651}$ Os Lóios do Porto: uma perspetiva integrada no panorama funerário da Baixa Idade Média à Época Moderna em meios urbanos em Portugal

Ana Lema Seabra

1659 O Caminho Português Interior de Santiago como eixo viário na Idade Média Pedro Azevedo

1665 Morfologia Urbana: Um exercício em torno do Castelo de Ourém André Donas-Botto / Jaqueline Pereira

1677 Intervenção arqueológica na Rua Marquês de Pombal/Largo do Espírito Santo (Bucelas, Loures)

Florbela Estêvão / Nathalie Antunes-Ferreira / Dário Ramos Neves / Inês Lisboa

1691 O Cemitério Medieval do Poço do Borratém e a espacialidade funerária na cidade de Lisboa Inês Belém / Vanessa Filipe / Vasco Noronha Vieira / Sónia Ferro / Rodrigo Banha da Silva

1705 Um Espaço Funerário Conventual do séc. XV em Lisboa: o caso do Convento de São Domingos da Cidade Sérgio Pedroso / Sílvia Casimiro / Rodrigo Banha da Silva / Francisca Alves Cardoso

\section{9. Época Moderna e Contemporânea}

1721 Arqueologia Moderna em Portugal: algumas reflexões críticas em torno da quantificação de conjuntos cerâmicos e suas inferências históricas e antropológicas Rodrigo Banha da Silva / André Bargão / Sara da Cruz Ferreira

1733 Faianças de dois contextos entre os finais do século XVI e XVIII do Palácio dos Condes de Penafiel, Lisboa

Martim Lopes / Tomás Mesquita 
1747 Um perfil de consumo do século XVIII na foz do Tejo: O caso do Mercado da Ribeira, Lisboa Sara da Cruz Ferreira / Rodrigo Banha da Silva / André Bargão

1761 Os Cachimbos dos Séculos XVII e XVIII do Palácio Mesquitela e Convento dos Inglesinhos (Lisboa)

Inês Simão / Marina Pinto / João Pimenta / Sara da Cruz Ferreira / André Bargão / Rodrigo Banha da Silva

1775 "Tomar os fumos da erua que chamão em Portugal erua sancta». Estudo de Cachimbos provenientes da Rua do Terreiro do Trigo, Lisboa

Miguel Martins de Sousa / José Pedro Henriques / Vanessa Galiza Filipe

1787 Cachimbos de Barro Caulínitico da Sé da Cidade Velha (República de Cabo Verde)

Rodrigo Banha da Silva / João Pimenta / Clementino Amaro

1801 Algumas considerações sobre espólio não cerâmico recuperado no Largo de Jesus (Lisboa) Carlos Boavida

1815 Adereços de vidro, dos séculos XVI-XVIII, procedentes do antigo Convento de Santana de Lisboa (anéis, braceletes e contas)

Joana Gonçalves / Rosa Varela Gomes / Mário Varela Gomes

1837 Da ostentação, luxo e poder à simplicidade do uso quotidiano: arqueologia e simbologia de joias e adornos da Idade Moderna Portuguesa Jéssica Iglésias

1849 Os amuletos em Portugal - dos objetos às superstições: o coral vermelho Alexandra Vieira

1865 Cerâmicas de Vila Franca de Xira nos séculos XV e XVI Eva Pires

1879 «Não passa por teu o que me pertence». Marcas de individualização associadas a faianças do Convento de Nossa Senhora de Aracoeli, Alcácer do Sal Catarina Parreira / Íris Fragoso / Miguel Martins de Sousa

1891 Cerâmica de Leiria: alguns focos de produção

Jaqueline Pereira / André Donas-Botto

1901 Os Fornos na Rua da Biquinha, em Óbidos Hugo Silva / Filipe Oliveira

1909 A casa de Pêro Fernandes, contador dos contos de D. Manuel I: o sítio arqueológico da Silha do Alferes, Seixal (século XVI) Mariana Nunes Ferreira

1921 O Alto da Vigia (Sintra) e a vigilância e defesa da costa Alexandre Gonçalves / Sandra Santos

1937 O contexto da torre sineira da Igreja de Santa Maria de Loures Paulo Calaveira / Martim Lopes

1949 A Necrópole do Hospital Militar do Castelo de São Jorge e as práticas funerárias na Lisboa de Época Moderna Susana Henriques / Liliana Matias de Carvalho / Ana Amarante / Sofia N. Wasterlain

1963 SAND - Sarilhos Grandes Entre dois Mundos: o adro da Igreja e a Paleobiologia dos ossos humanos recuperados

Paula Alves Pereira / Roger Lee Jesus / Bruno M. Magalhães

1975 Expansão urbana da vila de Cascais no século XVII e XVIII: a intervenção arqueológica na Rua da Vitória no 15 a 17

Tiago Pereira / Vanessa Filipe

1987 Novos dados para o conhecimento do Urbanismo de Faro em época Moderna Ana Rosa 
1995 Um exemplo de Arqueologia Urbana em Alcoutim: o Antigo Edifício dos CTT Marco Fernandes / Marta Dias / Alexandra Gradim / Virgílio Lopes / Susana Gómez Martínez

2007 Palácio dos Ferrazes (Rua das Flores/Rua da Vitória, Porto): a cocheira de Domingos Oliveira Maia

Francisco Raimundo

2021 As muitas vidas de um edifício urbano: História, Arqueologia e Antropologia no antigo Recreatório Paroquial de Penafiel Helena Bernardo / Jorge Sampaio / Marta Borges

2035 O convento de Nossa Senhora da Esperança de Ponta Delgada: o contributo da arqueologia para o conhecimento de um monumento identitário João Gonçalves Araújo / N’Zinga Oliveira

2047 Arqueologia na ilha do Corvo... em busca da capela de Nossa Senhora do Rosário Tânia Manuel Casimiro / José Luís Neto / Luís Borges / Pedro Parreira

2059 Perdidos à vista da Costa. Trabalhos arqueológicos subaquáticos na Barra do Tejo Jorge Freire / José Bettencourt / Augusto Salgado

2071 Arqueologia marítima em Cabo Verde: enquadramento e primeiros resultados do projecto CONCHA

José Bettencourt / Adilson Dias / Carlos Lima / Christelle Chouzenoux / Cristóvão Fonseca / Dúnia Pereira / Gonçalo Lopes / Inês Coelho / Jaylson Monteiro / José Lima / Maria Eugénia Alves / Patrícia Carvalho / Tiago Silva

2085 Trabalhos arqueológicos na Cidade Velha (Ribeira Grande de Santiago, Cabo Verde): reflexões sobre um projecto de investigação e divulgação patrimonial André Teixeira / Jaylson Monteiro / Mariana Mateus / Nireide Tavares / Cristovão Fonseca / Gonçalo C. Lopes / Joana Bento Torres / Dúnia Pereira / André Bargão / Aurélie Mayer / Bruno Zélie / Carlos Lima / Christelle Chouzenoux / Inês Henriques / Inês Pinto Coelho / José Lima / Patrícia Carvalho / Tiago Silva

2103 A antiga fortificação de Quelba / Khor Kalba (E.A.U.). Resultados de quatro campanhas de escavações, problemáticas e perspectivas futuras Rui Carita / Rosa Varela Gomes / Mário Varela Gomes / Kamyar Kamyad

2123 Colónias para homens novos: arqueologia da colonização agrária fascista no noroeste ibérico Xurxo Ayán Vila / José Mạ . Señorán Martín 


\title{
A ANTIGA FORTIFICAÇÃO DE QUELBA / KHOR KALBA (E.A.U.). RESULTADOS DE QUATRO CAMPANHAS DE ESCAVAÇÕES, PROBLEMÁTICAS E PERSPECTIVAS FUTURAS
}

\author{
Rui Carita ${ }^{1}$, Rosa Varela Gomes ${ }^{2}$, Mário Varela Gomes ${ }^{3}$, Kamyar Kamyad ${ }^{4}$
}

\begin{abstract}
RESUMO
Quatro curtas campanhas de escavações arqueológicas, efectuadas de 2017 a 2020, conduziram à identificação de ruínas da antiga fortaleza de Quelba/Khor Kalba (Emirado de Sharjah), na costa do Golfo de Omã, que os portugueses, sob o comando de Gaspar Leite, tomaram em 1624 e onde terão permanecido cerca de duas décadas. A fortificação foi construída em taipa, apenas parcialmente assente em alicerces de pedra, possuía planta de forma quadrangular, medindo $50 \mathrm{~m}$ de lado e era protegida, pelo menos nos dois cantos voltados para o mar, por torres de planta circular.

No seu interior identificámos solos de ocupação, de gesso e areia, buracos de poste de casas, fornos culinários, estruturas de combustão, lixeiras e um poço, assim como diversificado espólio, nomeadamente cerâmicas, datável entre os finais do século XVI e o século XVIII.

Palavras-chave: Emirados Árabes Unidos, Quelba/Khor Kalba, Fortificação portuguesa, Século XVII, Poço.
\end{abstract}

\begin{abstract}
Four brief archaeological digging campaigns, taking place from 2017 to 2020, lead to the identification of the old Quelba/Khor Kalba (Sharjah Emirate) fortress remains, on the Oman Gulf coast, where the Portuguese, under the Gaspar Leite command, took in 1624 and they stayed about two decades.

The fortress was built with mud walls, only partially laying on stone foundations, with quadrangular shape plan, measuring $50 \mathrm{~m}$ each side, and was protected, at least, on the two corners turned to the see, by circular plan towers.

Inside the fortification walls we have found living floors made with gypsum and sand, house postholes, ovens, fire places, dirt pits and a well, as diversified artefacts remains, namely ceramics, that we can date between the late $16^{\text {th }}$ and $18^{\text {th }}$ centuries.
\end{abstract}

Keywords: United Arab Emirates, Quelba/Khor Kalba, Portuguese fort, $17^{\text {th }}$ century, Well.

\section{INTRODUÇÃO}

Convite do Emir de Sharjah (E.A.U.), Sua Alteza Xeque Doutor Sultão bin Muhammad Al-Qasimi, endereçado a um de nós (RC) e o apoio da Autoridade para a Arqueologia de Sharjah (AAS), permitiu que efectuássemos visita de prospecção àquele emirado e ali dirigíssemos, depois, quatro curtas campanhas de escavações arqueológicas, de 2017 a 2020, ao abrigo de protocolo efectuado entre a AAS e a NOVA

\footnotetext{
1. IAP/NOVA FCSH, Univ. Madeira, Acad. Portuguesa da História, AAP; ruicarita@gmail.com

2. IAP/NOVA FCSH, AAP; rv.gomes@fcsh.unl.pt

3. IAP/NOVA FCSH, Acad. Portuguesa da História, Acad. Nacional de Belas-Artes, AAP; mv.gomes@fcsh.unl.pt

4. Sharjah Archaeology Authority; kmr.kmb@gmail.com
} 
FCSH, através do Instituto de Arqueologia e Paleociências (IAP). Fomos coadjuvados em tal tarefa por uma dezena de alunos, dos três níveis de ensino e ex-alunos, do Curso de Arqueologia da NOVA FCSH, no sítio de Khor Kalba, onde os portugueses ocuparam fortificação, durante duas décadas, que denominaram Quelba. Colaboraram naqueles trabalhos, em datas distintas, os Profs Doutores Fernando Almeida (Univ. de Aveiro) e Pedro Callapez (Univ. de Coimbra), neles participando trabalhadores não especializados da AAS, paquistaneses, indianos e tanzanianos. Os trabalhos de gabinete contaram com a prestimosa colaboração dos Profs Doutores Pedro A. Dinis (Univ. de Coimbra), Miguel Telles Antunes (NOVA FCT e Academia das Ciências de Lisboa), Luís Filipe Vieira Ferreira e Inês Ferreira Machado (Instituto Superior Técnico), Carmen Barceló Torres (Univ. de Valência) e Dr. José Pedro Henriques (IAP / NOVA FCSH).

A antiga fortificação de Quelba/Khor Kalba encontra-se mencionada no álbum das fortalezas da Índia, elaborado por Manuel Godinho de Erédia ( $c a$ 1563-1623) e outros, datado de pouco depois de 1622, mas com desenhos anteriores e ulteriores, hoje na Biblioteca da Fortaleza de São Julião da Barra. Pouco mais de uma década depois surgirá o Livro das Plantas de Todas as Fortalezas, Cidades e Povoações do Estado da Índia Oriental, de 1635, da autoria de António Bocarro, o cronista oficial do Estado da Índia e guarda-mor do Arquivo de Goa (ca 1594-1642), no que foi auxiliado nas suas representações gráficas pelo secretário do vice-rei, Pedro Barreto de Resende e, por certo, iluminadores luso-orientais. Desta obra manuscrita existem várias versões (Carita, 1999).

Em 1639, António de Mariz Carneiro fez uma breve descrição das fortalezas da costa do Golfo de Omã, onde de igual modo consta referência a Quelba.

Os parcos testemunhos chegados até nós da antiga fortificação de Quelba/Khor Kalba situam-se em planície litoral costeira do Golfo de Omã, imediatamente a norte do estuário do rio Kalba e a cerca de $500 \mathrm{~m}$ do Oceano Índico.

Antigo ponto de chegada das caravanas vindas do interior e do sul da Península Arábica, com conexão com as rotas litorais, tanto terrestres como marítimas, desde cedo que Khor Kalba obteve importância nas redes comerciais e estratégicas daquela costa, situada entre dois grandes emporia, a norte Ormuz e, a sul, Mascate.

Depois da passagem de Afonso de Albuquerque pela zona, a presença portuguesa em Quelba/Khor Kalba efectiva-se sob o comando de Gaspar Leite, em 1624, incluída no ambicioso plano de domínio do Golfo Arábico, das costas do Índico e Mar Vermelho, de Rui Freire de Andrade. Todavia, em 1648, quando é assinado tratado de paz na praia de Reame, entre o capitão-general de Mascate, D. Gil Eanes de Noronha e os xeques locais, já Quelba/Khor Kalba não surge entre as possessões portuguesas, embora o antigo xeque da mesma, Yusuf ben Ali ben Salih Al-Qasi$\mathrm{mi}$, se encontrasse presente. Deduz-se, assim, que aquela fortificação já havia sido entregue (Al-Salimi e Jansen, 2015: 385-388).

Foram publicados alguns trabalhos que dão a conhecer os resultados das primeiras campanhas arqueológicas de Quelba/Khor Kalba (Gomes et alii, 2017; Carita et alii 2019; 2019a). Algum espólio, dali procedente, integra a exposição Identidade e Cultura. Património Arqueológico de Sharjah (EAU), inaugurada em Novembro de 2019, no Museu Nacional de Arqueologia e de que se editou o catálogo respectivo (Gomes, 2019).

\section{PRINCIPAIS PROBLEMÁTICAS}

Os restos da fortificação de Quelba/Khor Kalba, desmontada segundo a tradição oral e a informação arqueológica, no século XVIII, por o mar chegar às suas muralhas, encontravam-se, à data do início dos nossos trabalhos, completamente submersos no terreno arenoso característico daquela área costeira. Todavia, eles haviam estado integrados em área fortemente ocupada por bairro de pescadores, depois arrasado tendo em vista efectivar moderna urbanização da zona. Esta integra extensas praias, bonita avenida marginal e área de reserva natural correspondente a mangal, que se desenvolve nas margens do Khor Kalba.

Constituiu importante desafio que enformou o nosso projecto de investigação em Quelba/Khor Kalba encontrarmos vestígios da sua antiga fortificação e materiais arqueológicos que, de algum modo, denunciassem a presença portuguesa; aspecto difícil, dada a fugaz ocupação portuguesa da edificação, ao que parece não alterada pelos portugueses e deixada sob a guarda e administração de comandante e tropas lascarins, ou seja de mercenários, com possível origem no Irão. Se estes objectivos não puderam ser plenamente concretizados, exumámos artefactos, ou os seus fragmentos, cuja origem é clara, mesmo 
quando exógenos, continuando relações há muito anteriores à presença portuguesa, embora outros tanto foram usados por portugueses como por populações estrangeiras e autóctones. Talvez algumas marcas de jogo, elaboradas sobre fragmentos de cerâmica, indiquem a presença portuguesa, dado que entre certas populações islâmicas a prática do jogo não é permitida.

Importa referir que a colecção artefactual exumada é constituída por conjunto de utensílios e restos de talhe, de pedra lascada e picotada/polida, correspondendo a pré-existências, anteriores à edificação do dispositivo defensivo que temos vindo a mencionar, sendo contemporâneos deste, numismas safávidas e outros artefactos de bronze, fragmentos de objectos de vidro e de concha, assim como copiosa colecção de cerâmicas, que incluem produções locais ou regionais, peças importadas do Irão e, em menor número, da China, assim como restos osteológicos de mamíferos, aves e peixes, a par de abundantes exemplares malacológicos (Antunes, 2019; 2019a; Callapez e Dinis, 2019; 2019a).

\section{A FORTALEZA}

Os testemunhos da antiga fortaleza, com planta aproximadamente quadrangular, medindo em cada lado cerca de $50 \mathrm{~m}$ (= 15 qala), encontrava-se orientada segundo a direcção dos pontos cardeais e era provida de torre circular, no canto sudeste, $\operatorname{com} 7,5$ $\mathrm{m}$ de diâmetro (= 4 qasaba). $\mathrm{O}$ canto sudoeste apresentaria torre com forma e dimensões semelhantes à referida. As paredes possuíam 2,35 $\mathrm{m}$ de espessura e eram construídas em taipa, pedra e gesso, ou seja, "à maneira dos mouros" conforme mencionaram Bocarro e Erédia.

Fortalezas com planta quadrangular, com torres circulares a cada canto, ou apenas com duas torres, erguidas em pedra, taipa ou adobe, têm longa tradição, ocorrendo no Norte de África, Mediterrâneo Oriental e Próximo Oriente, durante a Antiguidade Tardia, devido à difusão da presença romana e bizantina, persistindo nos inícios da Idade Moderna e, até, depois desta.

No Limes Arabicus, estabelecido depois da conquista e anexação da Península Arábica, sob a administração de Trajano em 106 A.D., foram construídas fortalezas durante o reino de Septímio Severo (196-211 A.D.), possuindo torres redondas projectadas, nas paredes e nos ângulos, como acontece na forta- leza quadrangular de Ain Sinu no norte do Iraque (Lander, 1984: 132, 133). Qseir es-Sele, na Síria, teve também um forte com planta quadrangular ( $37 \mathrm{~m} \mathrm{x}$ $37 \mathrm{~m}$ ), protegido por quatro torres de traçado circular, dispostas a cada canto, medindo $12 \mathrm{~m}$ de diâmetro. Esta construção é datada no Período da Tetrarquia (século III), quando as províncias romanas do Oriente eram administradas por Diocleciano (293-313) (Lander, 1984: 190, 192, 240). Existem também outros exemplos na Síria e, em Ed Dour (Emirado d'Umm al Quwain), foi escavada fortificação, edificada em pedra, com planta quadrangular, medindo $30 \mathrm{~m}$ de lado, protegida por torres circulares nos cantos, mostrando ocupação datada nos séculos II e III (Lecomte, 2018: 90-92). No Emirado de Sharjah, o forte de Dayd oferece planta de forma quadrada, com duas torres circulares nos cantos (Cardi e Doe, 1971: 240, 250, 255). Teria constituição semelhante o forte de Libidia/Bidiyya, cuja edificação é atribuída aos portugueses (1623), medindo cerca de $60 \mathrm{~m}$ de lado, com torres redondas (?) nos cantos (Ziolkowski, 1999; 2002, vol. II: 81). Também o forte de Al-Qurainiyah, a $450 \mathrm{~m}$ para sudeste da aldeia com o mesmo nome, na ilha de Failakah (Kuwait), próximo do mar, mostra planta de forma quadrangular. Mede $32 \mathrm{~m}$ em cada lado e era protegido por quatro torres de canto, com planta circular, possuindo 2,40 m de diâmetro. Esta fortaleza foi edificada pelos portugueses, em pedra local e, possivelmente, adobes (Laino, 2015).

A tradição refere que a antiga "fortaleza portuguesa” de Quelba/Khor Kalba foi arrasada, informação reiterada recentemente, dada a frequente inundação da área pelo mar. Uma outra fortificação, ainda hoje existente, foi erguida nas proximidades, junto da qual se situava aldeia de pescadores.

A fortaleza que os portugueses registaram através de desenhos, aparece com planta quadrangular, possuindo bastiões em cada canto, um dos quais mais alto e mais complexo, com plataforma, protegendo a entrada voltada a norte.

\section{SOLOS DE OCUPAÇÃO}

Foram reconhecidos e cuidadosamente postos à vista, dada a sua fragilidade, restos de pavimentos de massa de gesso, tanto no interior como nas áreas exteriores da fortificação, mas nas proximidades daquela, tanto no seu lado nascente como sul.

São superfícies horizontais, alisadas, assentes nas 
areias que correspondem ao solo da zona, e que conservam buracos de poste, com diâmetros que variam entre $0,120 \mathrm{~m} \mathrm{e} 0,260 \mathrm{~m}$. Alguns constituem alinhamentos, por vezes dispostos paralelamente, indicando terem sido usados para suportarem postes de casas, constituídos com toros e ramos de palmeira-tamareira, espécie muito comum na zona e de grande importância económica.

Tais casas (barasti) teriam plantas de forma rectangular, com $5 \mathrm{~m}$ a $6 \mathrm{~m}$ de comprimento, surgindo sobretudo orientadas no sentido nascente-poente, sendo idênticas a estruturas habitacionais, edificadas do mesmo modo e utilizadas até meados da passada centúria, nomeadamente pelas populações piscatórias da costa de Kalba.

\section{ESTRUTURAS DE COMBUSTÃO E FORNOS DOMÉSTICOS}

Nas áreas em torno do dispositivo defensivo, a norte, nascente e a sul, escavaram-se algumas estruturas de combustão, constituídas quase sempre por pequenas fossas abertas no solo, com contorno circular ou oval, reconhecíveis por conterem sedimentos de cor negra, carvões e algum espólio arqueológico. Este corresponde a fragmentos de cerâmica e mais raramente de vidro, restos de fauna, mamíferos, aves, peixes, decapodos e de moluscos marinhos, de diversas espécies.

Identificámos quatro fornos domésticos, usados sobretudo para cozer pão, três localizados no interior do recinto fortificado e um no exterior, junto à sua fachada voltada a sul. Três daquelas estruturas são muito semelhantes entre si e, também, às por nós descobertas no Ribāt da Arrifana e na aldeia piscatória da Ponta do Castelo, ambos arqueossítios islâmicos no concelho de Aljezur. Elas apresentam planta de forma subcircular, com a base constituída por massa compacta, cozida devido ao uso, e paredes erguidas com pequenas pedras e massa de gesso, ligeiramente inclinadas para o interior, denunciando forma troncocónica. Por vezes encontram-se associadas a manchas de cinzas, correspondentes ao seu uso. Todavia, um dos tānnur de Quelba/Khor Kalba (T3) reutilizou grande talha de cerâmica, colocada em posição invertida no solo e com o fundo amputado.

\section{FOSSA-LIXEIRA}

Durante a campanha de 2019 surgiu no lado sul da fortificação, pequena fossa, com planta de forma subcircular, $(\varnothing=0,60 \mathrm{~m})$ não muito profunda, contendo fragmentos de cerâmicas, nomeadamente de taças, uma delas vidrada nas cores castanha e verde, e de jarro, artefactos metálicos, em liga de cobre (numisma safávida, alfinete de cabelo e fragmento de espeto), um peso de rede de pedra, ossos de pequenos mamíferos e peixes, assim como conchas de moluscos marinhos.

$\mathrm{O}$ alfinete de cabelo, com $0,082 \mathrm{~m}$ de comprimento, possui secção circular e cabeça encurvada. Estes artefactos eram usados para unir elementos de vestuário, véu ao cabelo, ou como adornos. No Próximo Oriente, os alfinetes de cabelo metálicos são conhecidos desde o I milénio A.C., apresentando tal utilização grande continuidade devido à sua simplicidade e funcionalidade.

\section{ARTEFACTOS DE CERÂMICA}

Os trabalhos, tanto de prospecção sistemática da zona da fortificação e espaço imediatamente anexo, como a escavação, proporcionaram a descoberta de milhares de fragmentos de cerâmica. A maioria destes correspondem a recipientes, com formas e funções diversas, mas também se registaram marcas de jogo, fusaiolas e, até, contas, que reutilizam fragmentos daqueles primeiros.

Entre tal acervo, distingue-se pelas suas características peculiares, a porcelana chinesa, datável entre o século XVII e o XX, embora a maioria, procedente do nível de ocupação $\left(\mathrm{C}_{2}\right)$, possa ser atribuída ao século XVIII. Todavia, identificámos, macroscopicamente, mais sete classes de cerâmica, de que a seguir damos conta, e iniciámos a sua caracterização química (Ferreira et alii, 2019).

Faiança de Kerman. Durante o século XVII os fornos de Kerman, no Irão, produziram faiança com decoração fitomórfica, de cor azul cobalto sobre esmalte de cor branca mate, na tentativa de copiar a muito apreciada e dispendiosa porcelana chinesa do fim da dinastia Ming. Apesar de não ser muito comum nos arqueossítios da Península Arábica, aquela classe de cerâmica ocorre, como seria expectável, em alguns assentamentos costeiros do Golfo Arábico e do Golfo de Omã, como Julfār (Ras al-Khaimah), Kashm 
Nadir ou no forte de Wadi Haqil (Cardi e Doe, 1971: $249,250,268)$. Apesar de ser rara na antiga fortaleza de Quelba/Khor Kalba, ela ajuda a compreender a sua difusão, as rotas comerciais de então e as influências culturais, directas e indirectas.

Cerâmica vidrada de cor castanha clara. Produção atribuída ao Irão, talvez a Kung/Khunj, distingue-se muito bem das cerâmicas vidradas omanitas, de cor castanha ou verde, pois além da sua pasta muito fina e homogénea, não muito compacta, de cor amarela, apresenta vidrado espesso e brilhante, de cor castanha clara ou amarela, com aspecto melado. Esta produção pode ser datada dos séculos XVI e XVII, fazendo parte do pouco conhecido grupo das "Cerâmicas vidradas do Golfo", de T. Powel (2015: 11, 12). Todavia, alguns fragmentos de recipientes, parecendo pertencer ao mesmo tipo de produção, foram exumados nos dois fortes de Fili (al-Madam, Sharjah), onde se consideraram como não sendo anteriores ao século XVIII (Sasaki, Sasaki e Yousif, 2017: 5, Figura 1).

Cerâmicas vidradas de cor castanha ou verde, do tipo Bahlā. Trata-se de produções com pastas não muito homogéneas, mas compactas, cor-de-laranja ou vermelha, cozidas a altas temperaturas e cujas superfícies, uma, as duas ou apenas parte daquelas, receberam espesso vidrado de cor castanha clara, escura ou verde e, não raro, com pequenas manchas de cor castanha escura (mosqueado). Estas cerâmicas podem ter tido diversas origens, nomeadamente em Kung/Khunj (Irão), onde os portugueses tiveram feitoria, fundada por Rui Freire de Andrade, a partir de 1628 e até 1725 , mas foram também produzidas em Bahlā (Omã), onde a sua manufactura parece ter ocorrido desde o século XIII, tendo depois evoluído (sécs XVI e XVII) e chegando ao século XIX. Em Silhat (Sohar, Omã) esta classe de cerâmicas foi datada nos séculos XVI e XVII (Ziolkowski, 2002: 233-236, 373; Al-Salimi e Korn, 2008: 227, 228; Power, 2015: 10, 11). Nos dois fortes de Fili (al-Madam, Sharjah), esta cerâmica está representada e foi datada no século XVIII, ou até mais tarde (Sasaki, Sasaki e Yousif, 2017: 5, fig. 2). Alguns fragmentos procedentes da fortaleza de Khor Fakkan serão, por certo, do século XVII (Sasaki e Sasaki, 2017: 14).

Cerâmica com pintura sob vidrado. Esta classe de cerâmicas distingue-se, muito bem, através da sua técnica decorativa, acreditando-se que teve origem no Irão, em finais do século XII, de onde foi transmitida para o Iraque e Egipto. As produções iranianas individualizam-se das restantes, dado o uso de decoração geométrica, de cor negra ou violácea escura, de manganês, sob vidrado de cor azul-turquesa ou verde, muito claro. Apresenta pastas homogéneas, não muito compactas, de cor amarela clara. Pratos e taças, alguns de grande tamanho, constituem as principais formas identificadas, providas de fundo destacado, plano ou em anel. Em Sirāf, algumas cerâmicas desta classe, dataram-se do século XV, mas em Silhat (Sohar, Omã), exemplares do mesmo tipo foram classificados nos séculos XVI e XVII, admitindo-se, até, que possam ter sido usadas em datas mais recentes (Cardi e Doe, 1971: 267, 268; Ziolkowski, 2002: 231; Power, 2015: 12). De facto, em dois dos fortes de Fili (al-Madam, Sharjah), com ocupação não anterior ao século XVIII, encontraram-se fragmentos daquelas produções (Sasaki, Sasaki e Yousif. 2017: 5, fig. 1). Cardi e Doe (1971: 267, 268) identificaram dois grupos distintos de cerâmicas desta classe: uma pintada de azul ou preto, com vidrado de cor azul-turquesa clara e o outro com pinturas nas cores violeta, castanho escuro ou verde escuro, cobertas por vidrados de cor verde clara.

Cerâmica fina incisa ou impressa. Alguns fragmentos de cerâmicas, produzidas com pastas muito homogéneas e compactas, bem cozidas, em tons claros, de cor amarela ou rosada, com paredes finas, apresentando, nas superfícies exteriores, muito lisas, decoração incisa, impressa ou plásticas, de carácter geométrico, por vezes inserida em cartelas. Foram encontradas, tanto à superfície do terreno como no estrato de ocupação da antiga fortificação de Quel$\mathrm{ba} /$ Khor Kalba ( $\left.\mathrm{C}_{2}\right)$. Aqueles testemunhos arqueológicos provêm principalmente de recipientes fechados, jarros e cântaros, de pequenas ou médias dimensões, que serviam, para conter, servir, transportar ou armazenar, água ou outros líquidos. Acreditamos tratar-se de tipo de cerâmicas a que T. Power (2015: 6) chamou "branca incisa", muito comum nos Emirados e no Golfo do Omã, entre o século XVII e o XIX, talvez alcançando o século XX. Até agora a origem precisa de tal produção é desconhecida, embora se julgue provir de diferentes centros no Irão, ou talvez da Península Arábica. Fragmentos de recipientes desta classe de cerâmicas exumaram-se nos dois fortes de Fili (al-Madam, Sharjah), onde não 
serão anteriores, conforme atribuição do restante acervo da cultura material ali exumado, ao século XVIII (Sasaki, Sasaki e Yousif, 2017: 5, fig. 3). O mesmo tipo de cerâmica foi descoberto em Julfār (Ras al-Khaimah), Dibba e Kashm Nadir (Cardi e Doe, 1971: 249, 250, 270). Entre os jarros, a forma mais comum (tipo Julfār) é aquela que possui corpo bitroncocónico, gargalo alto e cilíndrico, longo bico e asa no lado oposto a ele, com secção semicircular, unindo o gargalo a ponto do volume mesial do corpo. Os fundos podem ser planos ou algo convexos (Ziolkowski, 2002: 227).

Cerâmicas de pastas escuras. Recipientes de pequenas, médias e grandes dimensões, foram produzidos com pastas pouco homogéneas e pouco compactas, contendo elementos não plásticos, de grão médio a grosseiro, sendo cozidas em ambiente redutor e apresentando o núcleo, assim como as superfícies, de cor castanha muito escura, cinzenta escura ou negra. Tais exemplares sugerem corresponder a manufactura local ou regional, que utilizou argilas e inclusões de origem metamórfica, de cores escuras, da família dos basaltos, gabros e grauvaques. Por vezes as superfícies daqueles recipientes receberam aguadas de cores escuras, castanha ou cinzenta, talvez para melhor isolarem as suas paredes ou por questão de gosto. É possível que as cerâmicas de pastas escuras procedam dos mesmos centros que produziram as de pastas vermelhas, dada a similaridade de formas e de cronologias existentes entre ambas. T. Power (2015: 7-9), inclui ambas classes de cerâmicas na categoria de "cerâmicas de Julfär".

Cerâmicas de pastas vermelhas. Correspondem a manufacturas locais e regionais, com tradição ancestral, montadas com pastas não muito homogéneas nem compactas, contendo elementos não plásticos, de grão fino a grosseiro, calibre que varia consoante a dimensão dos recipientes, mostrando pastas e superfícies de cor vermelha ou cor-de-laranja. Os centros produtores antigos são, por ora, desconhecidos, embora se saiba que al-Fara, perto de Wadi Miduk (Emirado de Fujeira) produziu, até à segunda metade do passado século, cerâmicas deste tipo, com formas muito diversificadas (Ziolkowski, 2002: 228). Também em Lima, no norte do Omã, ainda se fazem cerâmicas seguindo os processos tradicionais (Al-Salimi e Korn, 2008: 279). Outros fornos podem ter cozido esta classe de cerâmicas, as mais comuns entre os séculos XII e XX, como as encontradas em Ras al-Khaimah e antiga Julfār (Cardi e Doe, 1971: 249, 250, 259; Power, 2015: 7). T. Power (2015: 8, 9, fig. 5) distinguiu três tipos de panelas de cerâmica vermelha. $\mathrm{O}$ mais antigo, com bordo introvertido e pequenas pegas triangulares, aplicadas nos ombros, que datou nos séculos XVII e XVIII (Late Islamic I), como diversos exemplares recolhidos em Quelba/ Khor Kalba, um deles no alicerce da sua muralha. Alguns fragmentos apresentam aguada ou decoração pintada, como aqueles possuindo linhas de cor vermelha que encontrámos ou os precedentes dos dois fortes de Fili (Sasaki, Sasaki e Yousif, 2017: 7, fig. 11). Também se conhecem exemplares em Kashm Nadir, a sul de Ras al-Kaimah (Julfār) e em Sirāf, onde foram atribuídos ao século XV (Cardi e Doe, 1971: 250-271). Sectores de grandes jarras, para armazenamento, com decoração elaborada através de impressões digitadas, de Quelba/Khor Kalba, encontram paralelos em cerâmicas de cor vermelha escura, algumas delas apresentando engobe de cor cinzenta nas paredes exteriores e ornamentação digitada, dos dois fortes de Fili (al-Madam, Sharjah), espólio tido como não anterior ao século XVIII. Procede deste mesmo arqueossítio tampa de panela de cerâmica, embora algo diferente dos exemplares exumados em Quelba/Khor Kalba (Sasaki, Sasaki e Yousif, 2017: 6, 7, figs 4, 6, 12). (Quadro 1)

\section{FUSAIOLAS E MARCAS DE JOGO}

Uma fusaiola reutiliza fundo de taça de cerâmica, com pé anelar, aspecto que oferece paralelos em exemplares do Forte Ocidental de Corfacão (Sasaki e Sasaki, 2017: 15) e em outros sítios arqueológicos da Península Arábica. Fusaiola de cerâmica foi encontrada na aldeia de Luliyah, do século XIII. Também de Bydiyya provêm exemplares que utilizam fragmentos de recipientes de cerâmica (Ziolkowski, 2002: 371).

A prática de fiar foi corrente na Europa, desde a Pré-História até aos tempos actuais, onde fragmentos de cerâmica foram reutilizados em fusaiolas ou balanços de fusos. As fusaiolas são conhecidas nas margens do Mediterrâneo desde o IV milénio A.C. A morfologia daqueles artefactos foi mudando desde então, podendo ser esférica, esférica achatada, hemisférica, cónica, bitroncocónica ou cilíndrica, com diversas dimensões e matérias-primas, como pedra, cerâmica, osso e até metal. 
As fusaiolas, usadas nos fusos, são indicadores da fiação de fibras vegetais (linho, algodão) ou animais (lã) formando fios, usados na manufactura de têxteis, tarefa executada no contexto familiar, geralmente atribuída à esfera feminina, a única produção artesanal até agora identificada em Quelba/Khor Kalba.

Marca de jogo obtida a partir do fundo de taça vidrada, de cor verde azeitona, e as produzidas com fragmentos de panelas ou recipientes de armazenamento, indicam prática, detectada nas margens do Mediterrâneo e na Península Ibérica, desde o Neolítico Final e Calcolítico (IV milénio A.C.) até à Idade Contemporânea (Gomes, Ninitas e Borralho, 2012-13: 17, 53; Gomes, 2015: 51, 107).

Tais artefactos, normalmente produzido em pedra, cerâmica ou osso, e com diferentes dimensões, são conhecidos em contextos islâmicos, tanto urbanos como rurais, desde o oriente da Península Arábica (Rasal-Khaimah, Khor Fakkan, Quelba/Khor Kalba), até à Península Ibérica, entre o século X e o XV, assim como mais tarde, em contextos cristãos. Eles denunciam actividades lúdicas e meio de socialização, próprio de todas as idades e, talvez, de ambos os géneros, embora os jogos de azar (quinar) sejam proibidos pelas leis islâmicas (Gomes e Gomes, 2007: 107-109).

Peças de madeira ou cerâmica, e lajes de pedra, foram usadas como tabuleiros para aqueles entretenimentos, com espaços definidos por linhas incisas ou série de covinhas, e eles podiam também ser improvisados no solo ou em diferentes tipos de pavimentos.

\section{ARTEFACTOS DE VIDRO}

Numerosos fragmentos de braceletes de vidro, mostram corpo maciço, com secção plano-convexa ou semicircular, embora ligeiramente apontada. Somente um deles possui secção elíptica e é oco. As braceletes foram produzidas em vidro opaco, preto ou azul escuro, mas também translúcido de cor castanha, medindo entre 0,05 m e o,10 m de diâmetro.

Porções de braceletes de vidro negro ou azul escuro opaco, sem decoração, datadas do século VII ao século XII, foram encontrados na área de habitat de A’Ali (Ilha do Barém) (Sasaki e Sasaki, 2011: 24). Ainda no Barém, em Barbar-Sud, identificaram-se exemplares lisos e torsos, atribuídos ao século XVIII (Ziolkowski, 2002: 369). Outros fragmentos de artefactos similares, foram escavados em Ras al-Khaimah, Kashm Nadir, ao sul de Ras al-Khaimah e em
Husaiyy (Cardi e Doe, 1971: 250-257; Shindo, 2001: 77). Exemplares de Bídia, um deles torcido, possuem cronologias situadas entre os séculos XIV e XVIII (Ziolkowski, 2002: 368, 376).

Descobriram-se doze fragmentos de braceletes de vidro negro em Sa'îdi (al-Qurainīyah) e um fragmento, com cor verde escura, provém de al-Qusūr (Ilha de Failakah), sendo ambos lugares com presença portuguesa, podendo ser datados nos séculos XVI e XVII. As suas medidas variam entre $0,05 \mathrm{~m}$ e 0,08 $\mathrm{m}$ de diâmetro. Outros exemplares, detectados em Ormuz apresentam diacronia mais ampla, do século XIV ao século XVII. Em al-Huwailah (Qatar), peças semelhantes foram datadas no século XVIII (Patitucci e Uggeri, 1984: 75, 78, 82, 88, 113-115, 200, 374, 375). Também foram exumados fragmentos de braceletes em Julfar, Wadi Masilah (Iémen), Jazirat al-Hulayla e al-Hasa (Arábia Saudita), com cronologias entre os séculos XI e o XIII (Whitcomb, 1983: 106; Vogt, 1994: 142, 143, 158). Outros foram exumados em Tell Abu Sarbut e em Khirbat Faris, na Jordânia, talvez procedentes de Hebron (Palestina) (Boulogne e Henderson, 2009). Exemplares de Quseir al-Qadim, no Egipto, medindo entre o,o4 m e o,o6 m de diâmetro, nas cores azul escura e negra, ou mais raramente azul clara e verde, planos e com secção triangular ou torcidos e de secção circular, podem ter origem nas manufacturas do Iémen (Adém) dos séculos XIII e XIV. Em cerca de 1258, Sa'di escreveu àcerca de comerciante que carregava vidro de Alepo para o lémen (Whitcomb, 1983: 106, 107).

Fragmentos de braceletes de vidro foram encontrados em Qasr-i Abu Nass no Irão (sécs XIII-XIV), outros em Samarra, Ana e Tell Gubba, no Iraque, e em contexto do século XVII, com presença portuguesa, no Forte de Jesus (Mombaça, Quénia) (sécs XVII-XIX), cuja origem foi atribuída a produção da Índia Oriental (Kirkman, 1974: 158, 317). Em outros sítios coloniais, portugueses e espanhóis, foram igualmente identificadas braceletes de vidro (Qsar es-Seguir, em Marrocos, sécs XV e XVI; La Isabella (1493-98), na República Dominicana ou em Puerto Real, no Haiti (1503-78) (Deagan, 2002: 134, 135). Com longa tradição no subcontinente indiano e no Mundo Islâmico, tal como na Europa onde remontam à Idade do Ferro (La Tène, sécs III - I A.C.), as braceletes de vidro foram produzidas na Anatólia (Tyana, Kermeshisar), do século III ao XI, Síria (Qsar el-Hayr), Palestina (Hebron, sécs XIV-XIX), Sinai (al-Tūr), Iémen (Kawd am-Saila, 
Shabwr, Shihr, Adém) (sécs IV-XVI), Qatar, Egipto (al-Fustat, nos séculos IX-XIV e Quseir al-Qasim), Etiópia e na Índia (Sankalia, séc. XIV, Brahmapuri e Arikamedu, na Costa do Coromandel) (Whitcomb, 1983: 106; Patitucci e Uggeri, 1984: 374, 375; Spaer, 1994: 46, 48, 57; Shindo, 2001: 74; Boulogne e Henderson, 2009; Zanon, 2013). As braceletes de vidro, lisas, com secção circular, oval e plano-convexa, torcidas em espiral, simples ou com aplicações e cabos, foram usadas no Próximo e Médio Oriente, tal como na Europa, por adolescentes, mulheres jovens e até por crianças, nos braços e pernas, por vezes em pares ou em conjuntos maiores, medindo entre $0,05 \mathrm{~m} \mathrm{e}$ o,o8 m de diâmetro. As de menores dimensões podiam também ser penduradas em colares (Malalana Ureña, 1997: 306, 309-311).

A enorme difusão das braceletes de vidro, pode, por certo, dever-se a distintos factores: por constituírem adereços não muito dispendiosos, mas vistosos, por produzirem som quando entrechocam, usadas nos pulsos ou tornozelos, mas também por mostrarem, na maioria dos casos, cor negra, como a do azeviche e, acreditar-se conterem as propriedades profilácticas e talismânicas daquele mineral, ou cor azul, como a cor da abóbada celeste, mas ainda por serem de forma circular. Para M. Spaer (1994:56), os séculos XIV e XV "podem ser vistos como a Idade dourada das braceletes de vidro islâmico".

Também se encontraram aplicadores de kohl e fragmentos de garrafas, de vidro, talvez holandesas, do século XVII.

Duas contas apresentam forma esférica e cor azul celeste, uma tem forma esférica achatada e é de vidro translúcido e uma outra, mais recente, apresenta forma cilíndrica e cor laranja. Esta deve ser originária do subcontinente indiano e datar dos inícios do século XX. As contas esféricas de cor azul podem ter origem chinesa, de $c a 1800$ e foram muito difundidas, chegando ao continente americano, através dos missionários católicos, pelo que ali são conhecidas por "padre beads" (Francis, 1994: 86). Conta mais antiga foi produzida em vidro translúcido.

As contas de vidro constituem adornos atraentes à vista, devido às formas e cores que apresentam, sendo duráveis, usados desde os tempos proto-históricos e depois em todo o mundo. Segundo antigas crenças, as contas de cor azul, como as de vidro ou na rocha semipreciosa que é o lápis-lazúli, simbolizam a noite estrelada e o céu, protegendo contra o mau-olhado. O valor apotropaico dos colares de contas assenta na ideia de que aquelas, sendo esféricas, traduzem a imagem e o conceito de perfeição e ordem, quando em colares, simbolizam a unidade cósmica do múltiplo. Contas de vidro, produzidas no subcontinente indiano, certamente chegaram à Península Arábica, talvez importadas de Chaúl, porto de comércio e centro de produção de tais adereços (Dussubieux et alii, 2008).

\section{PEDRAS DE FUNDA}

Na área da antiga fortificação de Quelba/Khor Kalba encontraram-se pedras de funda, de rochas com cor branca, cinzenta escura ou negra, mas com dimensões e pesos semelhantes. Pequenas pedras de funda foram identificadas nas ruínas do sítio de A'Ali (Ilha de Barém), datadas entre os séculos VIII e XII (Sasaki e Sasaki, 2011: 24).

Não é raro surgirem, em contextos pré-históricos de diferentes cronologias, artefactos esféricos, talhados em diferentes rochas e com distintas dimensões. Eles são, por vezes, denominados "esferas de pedra" e as possíveis funções que lhes são atribuídas geralmente compreendem duas vastas categorias: a dos percutores e a das armas de arremesso. Artefactos similares são conhecidos em períodos históricos subsequentes, até à Idade Moderna, onde foram usados como pedras de funda, os mais pequenos, e os maiores como balas de canhão ou catapulta, medindo até mais de o,40 $\mathrm{m}$ de diâmetro.

Não podemos afastar a hipótese de que alguns daqueles artefactos, com diâmetros medindo entre 0,06 $\mathrm{m}$ e 0,10 $\mathrm{m}$, tenham pertencido a bolas, armas de arremesso conhecidas desde a Pré-História e até aos nossos dias.

A funda (funda em latim) é arma rudimentar, mas eficaz, feita de tiras de couro ou tecida com fibras de origem vegetal ou animal, que usa a força centrifuga, transferida pelo braço humano, como meio de propulsão. Trata-se de elemento cultural primitivo, usado desde o Paleolítico Superior, ou talvez desde o Paleolítico Médio, resultando de invenção policentrada ou tendo difusão quase universal, embora mostre maior concentração nas margens do Mediterrâneo, utilizado tanto pelas últimas sociedades de caçadores-recolectores como por muitas ulteriores, como armas de guerra ou de caça, no abate de animais de pequeno e médio porte, mas também na direcção, defesa e controlo dos rebanhos, particularmente de cabras e ovelhas, para afastar aves e outros 
predadores das terras agrícolas ou, como brinquedo ou entretenimento para crianças e jovens.

Empregue na região do Mar Egeu, frequentemente desde o Neolítico e sobretudo durante a Idade do Bronze (Rex González, 1953: 275-277; Vutiropoulos, 1991), este tipo de arma foi comum na Península Ibérica, desde o Neolítico (V milénio A.C.), pois têm sido encontradas pedras de funda em dólmenes portugueses, espanhóis, tal como em franceses e irlandeses, produzidas em diferentes rochas locais, com diâmetros medindo entre $0,02 \mathrm{~m} \mathrm{e} 0,07 \mathrm{~m}$, confirmando o valor votivo destes artefactos, sucedendo às funções primárias já indicadas (Eogan, 1990: 126).

Plínio-o-Antigo (23-75 A.D.) (Naturalis Historiae, VII, 57) atribuiu a invenção de tal arma de arremesso aos fenícios, apesar de ter sido largamente usada em tempos mais remotos e na Antiguidade, como alguma iconografia documenta, não só por aquele povo mas também por hititas, persas, assírios, mesopotâmios, egípcios, cretenses, gregos, etruscos e romanos.

Em Hassuna (Iraque) foram encontradas balas de cerâmica para funda, num contexto de 5000 A.C. (Korfmanm, 1973: 39). Howard Carter descobriu, em câmara anexa à do sarcófago de Toutankamon, cesto contendo brinquedos e algumas fundas, possivelmente usadas pelo faraó na sua infância. No chão, mas fazendo parte do mesmo conjunto, jaziam pequenos seixos, que aquele arqueólogo ligou às fundas (Lindblom, 1940: 13).

Conhecida passagem do Antigo Testamento (Primeiro Livro de Samuel), descreve o sucesso do jovem David, oitavo filho de Jessé, na luta contra o gigante filisteu e campeão Golias de Gath, abatendo-o com tiro certeiro de funda na testa.

Homero refere, na Ilíada, que os lócrios usaram fundas durante o cerco de Tróia, na costa da Anatólia. Políbio (IV, 61, 2) mencionou os atiradores de funda aqueus, que fizeram parte do exército de Filipe da Macedónia. Lívio (XX, 21, 12) escreveu acerca dos famosos funditores (atiradores com funda) da Mauritânia e das Ilhas Baleares (topónimo que parece derivar de ballai, significando em grego atirar) que, durante a Segunda Guerra Púnica (século II A.C.), combateram nas tropas do cartaginês Haníbal (Lindblom, 1940: 40). Todavia, para este autor os atiradores de funda aqueus foram, na Antiguidade, exímios (Korfmann, 1973: 39). Diodoro da Sicília reporta a presença dos atiradores de funda das Baleares, no sé- culo I A.C., durante a batalha de Eknomos, na qual os cartagineses derrotaram Agatodes de Siracusa.

As balas de funda são fáceis de obter, podendo servir a tal propósito, seixos naturalmente esféricos, ovóides ou poliédricos, de diferentes rochas, blocos com muito ou pouco trabalho de afeiçoamento, por lacagem e, em seguida, regularizados por picotagem e alguns até polidos. Podem também ser usadas esferas de cerâmica, tal como as que se descobriram em contextos calcolíticos no Sul de Portugal, e projécteis de materiais metálicos.

A forma esférica, aquela que permite maior balanço no lançamento, menores desvios da trajectória e, igualmente, melhor pontaria e eficiência, é a mais comum.

Dimensões e peso, que contribuem para os projécteis alcançarem maior distância, tal como a sua velocidade e força de impacto, pouco variam nos exemplares portugueses neolíticos e calcolíticos. Estes apresentam diâmetros que medem desde 0,030 m a o,054 m, com o,040 m de média e peso médio de $90 \mathrm{gr}$, algo menor que os exemplares do contexto histórico de Quelba/Khor Kalba (125 gr, 118 gr e 108 gr) (Gomes, Ninitas e Borralho, 2012-13: 38-42). Usadas em campo aberto, as fundas podem lançar pequenos projécteis, pesando entre 20 gr e 50 gr até $200 \mathrm{~m}$ de distância e a alta velocidade. Por exemplo, um projéctil com 30 gr pode alcançar a velocidade de $100 \mathrm{~km} /$ hora e assinalável impacto (Vutiroupolos, 1991: 279). Fundas mais robustas e atiradores treinados podem lançar balas até cerca de meio quilograma de peso e mais de o,1o m de diâmetro, capazes de causar danos sérios e, acima de tudo, a morte àqueles que sejam atingidos por elas (Gomes, 2002: 132-136).

\section{CONCHAS DINHEIRO}

A presença de conchas de Monetaria moneta (Linnaeus, 1758) e de Monetaria annulus (Linnaeus, 1758) na área da antiga fortificação de Quelba/ Khor Kalba pode derivar do seu uso como paleo-moeda, denominadas "conchas dinheiro ou moeda", "dinheiro de porcelana" ou cauris.

O nome cauri, difundido universalmente devido à designação hindi e urdu kauri, deriva da palavra em sânscrito kaparda. Aquelas conchas eram também conhecidas como porcelanas, da língua francesa e esta derivada do latim (pequeno porco), sendo ainda usada, pelos Portugueses e outros, a denominação búzios, em francês bouges, de onde derivam os 
termos boejies e boesies. Em árabe a sua designação é ouda (Quiggin, 1992: 26, 30).

O uso de cauris, como objecto de troca e representação, ascende no Mediterrâneo aos tempos pré-históricos, dado o facto de se terem recolhido exemplares de Monetaria moneta (Cypraea moneta) em contextos calcolíticos (III milénio A.C.) do Ocidente da Península Ibérica e, mais tarde, no mundo etrusco (Península Itálica), devido aos contactos ocorridos com o Mediterrâneo Oriental, onde aqueles já eram apreciados. De facto, parece que eles surgiram no Egipto pré-dinástico, na Síria e Mesopotâmia, ocorrendo durante o I milénio na África subsariana, onde o seu valor monetário era reconhecido e que, com algumas variantes, havia de permanecer até ao século XX.

Alguns túmulos, subterrâneos ou em abrigos, da enorme necrópole de Jebel al-Buhais (Sharjah), continham conchas de Monetaria moneta ou de Monetaria annulus, a maioria datada na Idade do Bronze (Período Wadi Suq, III milénio A.C.) (Jasim, 2018: $48,133,220,279$ ).

$\mathrm{Na}$ região de al-Madam (Sharjah), a $50 \mathrm{~km}$ da costa do Golfo de Omã, foram encontradas conchas de Monetaria annulus, em contextos arqueológicos dos séculos VI e V B.C. (Morales e Llorente-Rodríguez, 2016: 141).

Sulayman, um comerciante árabe, refere as conchas-moedas durante o século IX nas Ilhas Maldivas, o que é confirmado, na centúria seguinte, pelo historiador árabe Masudi de Bagdade (Quiggin, 1992: 28). El Bekri regista a presença, em 1068, de conchas-dinheiro no Sudão (Kangha), também mencionadas no Mali e Gao, durante o século XIV, por autores como Al-Omari e Ibn Battuta. O seu valor era então alto, dado que um dinar (moeda de ouro) valia 1150 cauris. Marco Polo escreveu, em 1297-98 acerca da importância monetária dos cauris, dizendo que eles eram aceites da Índia à China (Província de Yunnan). Em meados do século XV, Cadamosto, um italiano a trabalhar para a Coroa Portuguesa, observou o seu uso na Mauritânia e Leão Africano, no início do século XVI, atesta o seu apreço e valor, dado que quatrocentos cauris valiam um ducado (Saul, 1974: 79; Rivallain, 1986: 32, 33; Quiggin, 1992: 29, 31). No Daomé os cauris tiveram valor relativamente estável durante um século e meio, onde 32000 cauris valiam uma onça de ouro (Coquery-Vidrovitch, 1969: 75). Monetaria moneta (Linnaeus, 1758) e Monetaria annulus (Linnaeus, 1758), são moluscos gastrópodes pertencentes à família Cypraeidae (Rafinesque,
1815), que possui mais de cento e sessenta variedades (Lorenz e Hubert, 2002). O seu habitat são as águas profundas de "mares quentes", o Índico e o Pacífico. Todavia, aquela primeira espécie é mais comum na região de Lakshadweep (Ilhas Laquedivas) e Ilhas Maldivas, no sudoeste do subcontinente indiano, enquanto a segunda espécie é sobretudo encontrada nas águas da Ilha de Pemba, Zanzibar até Moçambique, na África Oriental, mas também no mar das Filipinas. As Maldivas eram conhecidas como Divah Kanzah ou Ilhas Cauri, e o maior centro de comercialização das conchas-dinheiro foi Bengal, conforme mencionado por Pyrard de Laval (Castro e Bouchon, 1998), nos inícios o século XVII (1601-1611), onde os Portugueses se abasteciam de cauris, tal como de pimenta e têxteis de algodão, bens depois transaccionados na China, trocados por arroz, ou na Costa do Malabar, Golfo Arábico e Mar Vermelho. Este comércio também ocorria em Goa e Cochim, de onde os produtos destinados à costa oriental de África, integravam o tráfico de escravos negros. Além de Bengal, Bombaim foi, durante o século XVI e de acordo com Gaspar Correa (séc. XVI) em "Lendas da Índia", um dos maiores portos de comércio de cauris (Sousa, 1967:41). Outros negociantes europeus interessaram-se pelo tráfico de cauris, como os holandeses (Saul, 1974: 80, 81; Quiggin, 1992: 27, 28, 30; Boyajian, 1993: 225).

Uma terceira espécie de cauri, a Cyprea errones, com concha similar às acima mencionadas e também com valor monetário reconhecido, é comum na área do Oceano Pacífico (Samoa, Tonga, Fiji, Ilhas Marshall e Filipinas) (Rivallain, 1985: 28, 29).

A partir do Oceano Pacífico e principalmente desde o Oceano Índico, o valor das conchas-moeda, ou dinheiro cauri, difundiu-se ao Afeganistão e à Pérsia e, através do Mar Vermelho, ao Mediterrâneo (Egipto e Maghreb). Dali passou para o Sudão e África subsariana, através de rotas caravaneiras, alcançando o Reino do Congo, como relataram Filippo Digafetta (1881), em 1591, e Olfert Dapper, em 1668, propagação que se ficou a dever a factores, como a sua origem oceânica e remota, forma, cor, brilho, dificuldade em partir-se e alterar-se, com valor igual, fácil de contar, manusear e transportar, impossível de contrafazer, mas também capaz de criar mitos e biografia simbólica, ligada à fecundidade e bem-estar (talismãs e amuletos). A sua grande dispersão, dado o uso do seu valor monetário, tal como ornamental e a conotação com conceitos mágicos (nomeada- 
mente apotropaicos), levou a que também estivesse presente em muitas zonas do Golfo Arábico, do Iémen, de África, da Ásia, América e Europa, através do comércio a longa distância proporcionado pela interacção colonial europeia.

Em meados do século XX, as autoridades coloniais de diversos países, asiáticos e africanos, procederam à desmonetização das moedas tradicionais, como os cauris, tendo em vista o melhor controlo das economias locais (Sousa, 1967: 15-20, 43; Rivallain, 1985: 265; Quiggin, 1992: 46, 47; Fuller, 2009: 60). Todavia, os cauris foram classificados como "o dinheiro mais longamente usado que o mundo alguma vez conheceu" (Saul, 1974: 77).

\section{CONCLUSÕES}

A presença portuguesa nas costas da Arábia recua aos inícios do século XVI e, um pouco depois, existiram entrepostos comerciais fortificados, tal como parece ter acontecido em Mascate e Soar, no actual Sultanato de Omã, ou em Khor Fakkan, no Emirado de Sharjah, de acordo com alguns registos antigos e escavações arqueológicas recentes naqueles sítios (Al-Qasimi, 2013; 2013a). No que concerne a Quelba/ Khor Kalba, os portugueses ali chegaram, em Março de 1624, e de acordo com o texto de Manuel Godinho de Erédia, a zona encontrava-se então sob a administração de um famoso líder da região, Al-Qasimi, certamente antepassado do actual Emir de Sharjah.

A guarnição portuguesa era constituída por um capitão lascarim com treze soldados com a mesma origem, recrutada na área de influência de Ormuz, actualmente Irão. Em princípio, a fortaleza não sofreu sérias reconstruções ou trabalhos de adaptação com a ocupação portuguesa. Ela foi abandonada pelos portugueses alguns anos depois, dado que a 30 de Outubro de 1648, foi assinado, o já mencionado tratado de paz entre Portugal e os xeques árabes, com a presença de Al-Qasimi, mas onde a fortificação de Quelba/Khor Kalba não é mencionada. O relacionamento comercial entre os portugueses e os líderes das tribos arábicas manteve-se por certo na região, porque beneficiava ambas partes, facto mencionado no tratado acima referido.

Confrontados com a tradição de que existiu uma fortaleza portuguesa em Quelba/Khor Kalba, quando a evidência arqueológica sugere indicar uma estrutura islâmica, somos conduzidos a reflectir se a presença portuguesa na área não ficaria aquém do mencionado nos documentos oficiais portugueses. $\mathrm{O}$ achado de numerosas moedas iranianas de baixo valor (safávidas), de fragmentos de artefactos de vidro e metálicos, a par de faiança iraniana e de fragmentos de porcelana chinesa, permite corroborar a ideia de que Quelba/Khor Kalba gozou de posição estratégica, continuada, como importante centro de comércio, com ocupação intensa, suportado por antigas rotas caravaneiras que atravessavam a Península Arábica ou por rotas marítimas, que tanto cruzaram o Golfo Arábico como o Oceano Índico, entre os séculos XVI e XVIII.

A colecção artefactual encontrada, durante os trabalhos arqueológicos de 2017-2020, traduz espécie de palimpsesto, onde se reconhece presença humana muito antiga (utensílios de pedra lascada ou picotada/polida) e testemunhos arqueológicos que evidenciam importantes relações económicas e culturais, mas igualmente a estratégia comercial e política então ocorrida na área da antiga fortaleza de Quelba/ Khor Kalba.

\section{BIBLIOGRAFIA}

ALMEIDA, Fernando (2019) - Khor Kalba UAE Mission Geophysical report, Annual Sharjah Archaeology, vol. 17: 137-160.

AL-QASIMI, Sultan bin Muhammad (2013) - Research of Fortress of Muscat and Other Forts in the Coast of Oman. Sharjah: Al Qasimi Publications.

AL-QASIMI, Sultan bin Muhammad (2013a) - Power Struggles and Trade in the Gulf 1620-1820. Sharjah: Al Qasimi Publications.

AL-SALIMI, Abdulrahman; JANSEN, Michael (2015) - Portugal in the Sea of Oman. Religion and Politics. Research on Documents, Corpus 1, Part 2, vol. 9 (Documents from 16421649). Hildesheim: Georg Olms Verlag.

AL-SALIMI, Abdulrahman; KORN, Heinz Gaube Lorenz (2008) - Islamic Art in Oman. Muscat: Sultanate of Oman.

ANTUNES, Miguel Telles (2019) - Preliminary report on the Palaeozoology, Annual Sharjah Archaeology, vol. 17: 165-174.

ANTUNES, Miguel Telles (2019a) - Preliminary palaeozoological report - mammals, birds and fishes, Annual Sharjah Archaeology, vol. 17: 305-313.

BOCARRO, António (1635) - Livro das Plantas de Todas as Fortalezas, Cidades e Povoações do Estado da Índia Oriental, com 52 desenhos de fortalezas de Pedro Barreto de Resende. Évora: Biblioteca Pública e Arquivo Distrital de Évora (Inv. CXV-2-1). 
BOULOGNE, Stéphanie; HENDERSON, Julian (2009) Indian glass in the Middle East? Medieval and Ottoman glass bangles from Central Jordan, Journal of Glass Studies, vol. 51, pp. 53-75.

BOYAJIAN, James C. (1993) - Portuguese Trade in Asia under the Habsburgs, 1580-1640. Baltimore/London: The Johns Hopkins University Press.

CALLAPEZ, Pedro Manuel; DINIS, Pedro Alexandre (2019) - Mollusc remains from the Quelba/Khor Kalba fortification (late $16^{\text {th }}$ to $18^{\text {th }}$ centuries, Sharjah, UAE): taxonomic, taphonomic, environmental and cultural implications, Annual Sharjah Archaeology, vol. 17: 175-216.

CALlAPEZ, Pedro Manuel; DINIS, Pedro Alexandre (2019a) - Edible crabs from Quelba/Khor Kalba fortification, Annual Sharjah Archaeology, vol. 17: 315-320.

CARDI, Beatrice de; DOE, Donald Brian (1971) - Archaeological survey in the Northern Trucial States, East $\mathbb{B}$ West, vol. $21(3,4)$, pp. 225-289.

CARITA, Rui (ed.) (1999) - O Lyvro de Plantaformas das Fortalezas da Índia (fac-simile do códice n- ${ }^{\circ} 1805$ da Biblioteca da Fortaleza de São Julião da Barra em Oeiras, Ministério da Defesa, atrib. a Manuel Godinho de Herédia, ca 1620/ ca. 1640). Lisboa: Edições Inapa.

CARITA, Rui; GOMES, Mário Varela; GOMES, Rosa Varela; KAMYAB, Kamyar Daryoush (2019) - The Portuguese Archaeological Mission at Sharjah (U.A.E.). Quelba/Khor Kalba - Report of the First Excavation Season (January 2017), Annual Sharjah Archaeology, vol. 17: 9-128.

CARITA, Rui; GOMES, Mário Varela; GOMES, Rosa Varela; KAMYAB, Kamyar Daryoush (2019) - The Portuguese Archaeological Mission at Sharjah (U.A.E.). Quelba/Khor Kalba - Report of the Second Excavation Season (January 2018), Annual Sharjah Archaeology, vol. 17: 219-303.

CARNEIRO, António de Mariz (1990) - Descrição da Fortaleza de Sofala e das mais da India com Huma Rellaçam das Religiões Todas q Há no Mesmo Estado (1639), Reprodução do códice iluminado 149 da Biblioteca Nacional de Lisboa. Lisboa: Fundação Oriente.

CASTRO, Xavier de; Bouchon, Geneviève (1998) - Voyage de Pyrard de Laval aux Indes Orientales (1601-1611), 2 vols. Paris: Éditions Chandeigne.

COQUERY-VODROVITCH, Catherine (1969) - Recherches sur un mode de production africain, La Pensée. Revue du Rationalisme Moderne, $\mathrm{n}^{\mathrm{o}}$ 144, pp. 61-78.

CORREA, Gaspar (1858) - Lendas da Índia, Tomo I. Lisboa: Typographia da Academia das Sciencias.

DEAGAN, Kathleen (2002) - Artifacts of the Spanish Colonies of Florida and the Caribbean 1500-180o, vol. 2 - Portable Personal Possessions. Washington: Smithsonian Institution Press.
DUSSUBIEUX, Laure; KUSIMBA, Chapurukha M.; GOGTE, Vaibhav; KUSIMBA, Sibel B.; GRATUZE Bernard; OKA, Rahul (2008) - The trading of ancient glass beads: new analytical data from South Asian and East African soda-alumina glass beads, Archaeometry, vol.5o(5), pp.797-821.

EOGAN, George (1990) - Irish megalithic tombs and Iberia: Comparisons and contrasts, Probleme der Megalithgräberforschung. Vorträge zum 100 Geburtstag von Vera Leisner, pp. 113-137. Berlin: Walter de Gruyter.

ERÉDIA, Manuel Godinho de (1610) - Plantas de Praças das Conquistas de Portugal Feytas por Ordem de Ruy Lourenço de Tavora Vizo rey da Índia (códice CAM - 3,5), Biblioteca Nacional do Rio de Janeiro.

ERÉDIA, Manuel Godinho de (atr.) (1999) - Lyvro das Plataformas das Fortalezas da Índia, fac-simile com estudo de Rui Carita de exemplar da Biblioteca da Fortaleza de São Julião da Barra. Lisboa: Ministério da Defesa e Inapa.

FERREIRA, Luís Filipe Vieira; MACHADO, Inês Ferreira; CARITA, Rui; GOMES, Rosa Varela; GOMES, Mário Varela; KAMYAB, Kamyar Daryoush (2019) - A preliminary characterization of four ceramic sherds found in a $17^{\text {th }}$ century deposite from the site of the primitive fort Quelba in the Sharjah Emirate, Annual Sharjah Archaeology, vol. 17: 161-164.

FRANCIS, Peter (1994) - Beads of the World. Atglen: Schiffer Publishing Ltd.

FULLER, Harcourt (2009) - From cowries to coins: Money and colonialism in the Gold Coast and British West Africa in the early $2 \mathrm{O}^{\text {th }}$ century, Money in Africa, pp. 54-61. London: The British Museum.

GOMES, Mário Varela (2002) - Cromeleque dos Almendres. Um Monumento Sócio-Religioso Neolítico. Lisboa: Faculdade de Ciências Sociais e Humanas da Universidade Nova de Lisboa.

GOMES, Mário Varela (2015) - The Vale da Telha Necropolis (Aljezur) in the context of the Southwest Iberian Bronze Age. Lisboa: Instituto de Arqueologia e Paleociências da Universidade Nova de Lisboa.

GOMES, Mário Varela (coord. edit.) (2019) - Identidade e Cultura. Património Arqueológico de Sharjah (EAU). Lisboa: Museu Nacional de Arqueologia, Sharja Archaeology Authority e Instituto de Arqueologia e Paleociências da Universidade Nova de Lisboa.

GOMES, Mário Varela; GOMES, Rosa Varela (2007) - Ribāt da Arrifana. Cultura Material e Espiritualidade. Aljezur: Município de Aljezur.

GOMES, Mário Varela; GOMES, Rosa Varela; CARITA, Rui; KAMYAB, Kamyar Daryoush (2017) - Resultados preliminares da primeira campanha da missão arqueológica portuguesa em Sharjah (EAU). Escavação Arqueológica em Quelba/Khor Kalba, Arqueologia em Portugal-2017. Estado 
da Questão: 1641-1657. Lisboa: Associação dos Arqueólogos Portugueses.

GOMES, Mário Varela; NINITAS, João; BORRALHO, Rita (2012-13) - Artefactos líticos do povoado calcolítico do Escoural (Montemor-o-Novo), Almansor, $2^{\underline{a}}$ série, $\mathrm{n}^{\circ}$ 10, pp. 5-6o.

JASIM, Sabah Abboud (2018) - The Necropolis of Jebel alBuhais, Prehistoric Discoveries in the Emirate of Sharjah, $2^{\text {nd }}$ edition. Sharjah: Sharjah Archaeology Authority.

KIRKMAN, James (1974) - Fort Jesus: a Portuguese Fortress on the East African Coast. Oxford: Clarendon Press.

KORFMANN, Manfred (1973) - The sling as a weapon, Scientific American, vol. 229, pp. 34-42.

LAINO, Raffaele (2015) - Otheractivities. Al Qurainiyah Fort, Kuwaiti - Italian Archaeological Mission at Failaka 20102014, pp. 70-72. Perugia: Università degli Studi di Perugia.

LANDER, James (1984) - Roman Stone Fortifications. Variation and Change from the First Century A.D. to the Fourth, British Archaeological Reports, International Series 206. Oxford: British Archaeological Reports.

LECOMTE, Olivier (2018) - Le site d'Ed Dour (Emirat d'Humm al Quwain, 40 Ans de Coopération Archéologique entre les Emirats Arabes Unis et la France, pp. 90-92. Sharjah: Sharjah Archaeology Authority.

LINDBLOM, Karl Gerhard (1940) - The Sling, Especially in Africa, Additional Notes to a Previous Paper. Stockholm: The Ethnographical Museum of Sweden.

LORENZ, Felix; HUBERT, Alex (2002) - A Guide to Worldwide Cowries, $2^{\text {nd }}$ revised edition. Hackenheim: Conchbooks.

MALALANA UREÑA, Antonio (1997) - Un conjunto de pulseras de vidrio hallado en la excavación del Hospital de San Andrés (Escalona, Toledo), Boletín de Arqueologia Medieval, vol. 11, pp. 293-312.

MORALES, Arturo; LLORENT-RODRÍGUEZ, Laura (2016) - Cíencias Físicas y Naturales e Historia, En los Confines de Oriente Próximo. El Hallazgo Moderno del País de Magán, pp. 141, 142. Madrid: Museo Arqueologico Nacional.

PATITUCCI, Stella; UGGERI, Giovanni (1984) - Failakah. Insediamenti Medievali Islamici. Ricerche e Scavinel Kuwait, Col. La Fenice. Roma: L’Erma di Bretschneider.

PIGAFETTA, Filippo (1881) - A Report of the Kingdom of Congo and the Surrounding Countries. London: John Murray.

POWER, Timothy (2015) - A first ceramic chronology for the Late Islamic Arabian Gulf, Journal of Islamic Archaeology, vol. 2(1), pp. 1-33.

QUIGGIN, Alison Hingston (1992) - A Survey of Primitive Money. The Beginnings of Currency, $2^{\text {nd }}$ ed. Ocala, Florida: First Impressions Printing Inc.
REX GONZÁLEZ, Alberto (1953) - La boleadora. Sus áreas de dispersión y tipos, Revista del Museo de la Universidad Eva Perón, vol. 4, pp. 133-292, XIV ests.

RIVALLAIN, Josette (1985) - Paléomonnaies africaines: formes et fonctions, Bulletin de la Société Préhistorique Française, vol. 82(9), pp. 265-269.

RIVALLAIN, Josette (1986) - Les Collections Monétaires VIII. Paléo-Monnaies Africaines. Paris: Administration des Monnaies et Médailles.

SASAKI, Tatsuo; SASAKI, Hanae (2011) - Excavations at A'Ali Islamic site, Bulletin of Archaeology, The University of Kanazawa, vol. 32, pp. 13-46.

SASAKI, Tatsuo; SASAKI, Hanae (2017) - Ceramics from Khor Fakkan West Fort, Emirate of Sharjah, United Arab Emirates (unpublished report), $32 \mathrm{pp}$.

SASAKI, Tatsuo; SASAKI, Hanae; YOUSIF, Eisa Abbas Hussein (2017) - Fili forts in al-Madam plain, Emirate of Sharjah, The United Arab Emirates, Japan Society for Hellenistic-Islam Archaeology Studies, vol. 24, pp. 83-116.

SAUL, Mary (1974) - Shells an Illustrated Guide to a Timeless and Fascinating World, Country Life. London: The Hamlyn Publishing Groups Limited.

SHINDO, Yoko (2001) - The classification and chronology of the Islamic glass bracelets from al-Tūr, Sinai, Senri Ethnological Studies, vol. 55, pp. 73-100.

SOUSA, Luís Rebelo de (1967) - Moedas de Angola. Luanda: Banco de Angola.

SPAER, Maud (1994) - The Islamic glass bracelets of Palestine: Preliminary findings, Journal of Glass Studies, vol. 34, pp. $44-62$.

VOGT, Burkhard (1994) - A lost late Islamic port on the South Arabian Coast, Bulletin of Archaeology. The University of Kanazawa, vol. 21, pp. 137-168.

VUTIROPOULOS, Nikos (1991) - The sling in the Aegean Bronze Age, Antiquity, vol. 65, pp. 278-286.

WHITCOMB, Donald S. (1983) - Quseir Islamic glass from Al-Qadim, Egypt, Journal of Glass Studies, vol. 25, pp. 101-108.

ZANON, Michela (2013) - Tyana/Kemerhisar (Nigde): glass bracelets of the Byzantine and Islamic period, Anatolia Antiqua, tomo 21, pp. 181-197.

ZIOLKOWSKI, Michele Christina (1999) - Excavations at Al-Bidiyya: new light on the Portuguese presence in the Emirates, Tribulus - Bulletin of the Emirates Natural History Groups, vol. 9 (2), pp. 19-21.

ZIOLKOWSKI, Michele Christina (2002) - The Historical Archaeology of the Coast of Fujairah, United Arab Emirates: From the Eve of Islam to the Early Twentieth Century, Vol. I: Text; Vol. II: Appendices. Sydney: University of Sydney. 


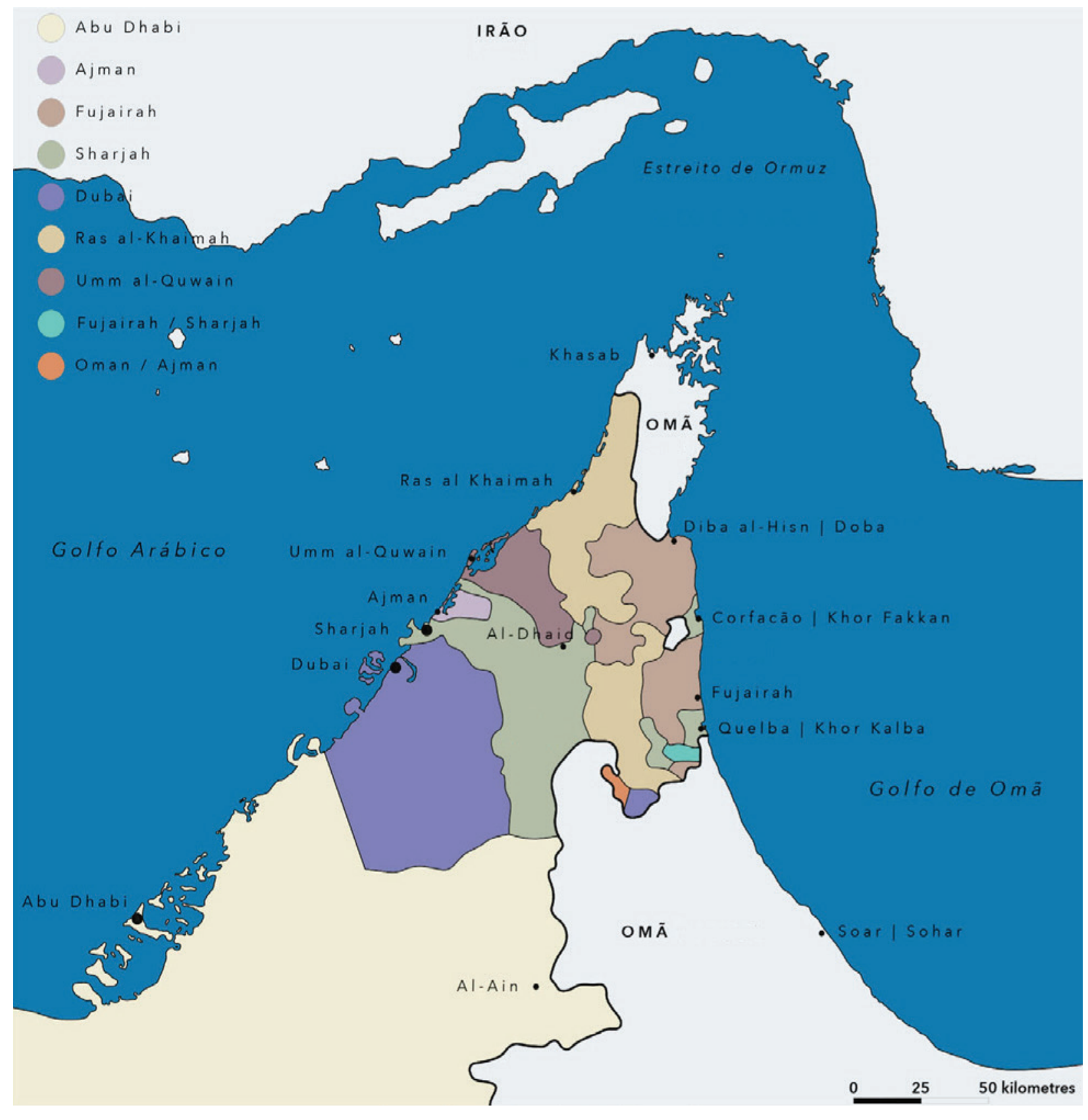

Figura 1 - Os Emirados Árabes Unidos e localização da antiga fortificação Quelba/Khor Kalba (Emirado de Sharjah). 

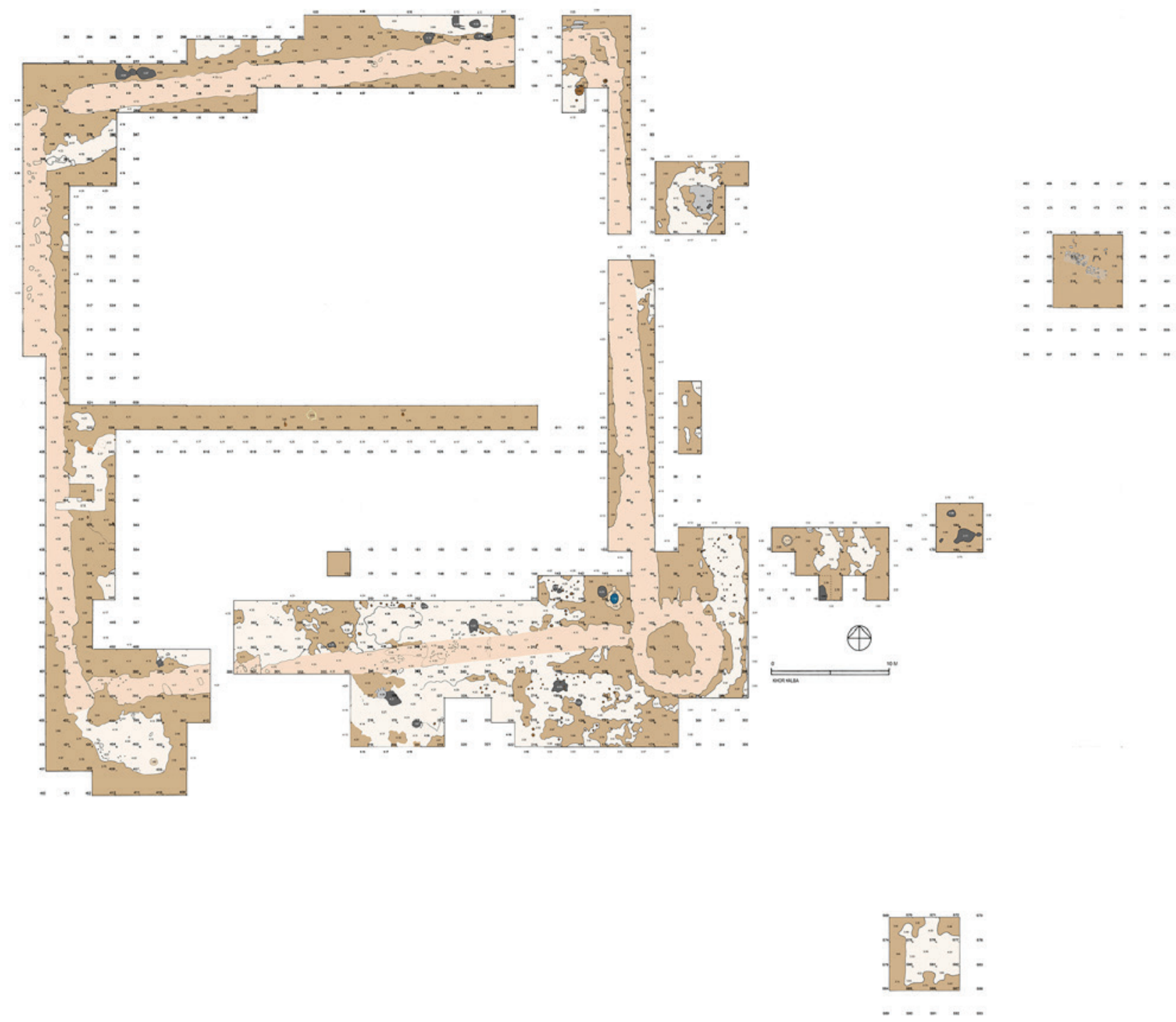

Figura 2 - Planta dos testemunhos arquitectónicos da antiga fortificação de Quelba/Khor Kalba (lev. J. Gonçalves, J. Iglésias e M.V. Gomes). 


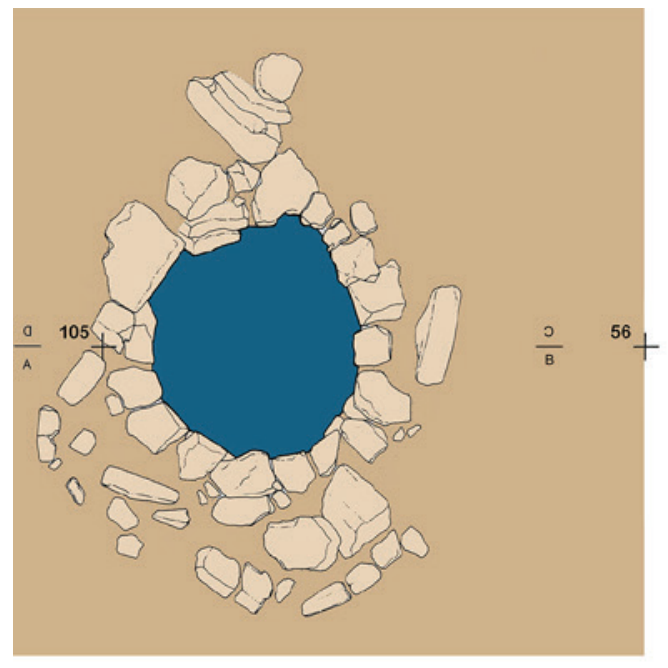

$\oplus$ $3^{m}$
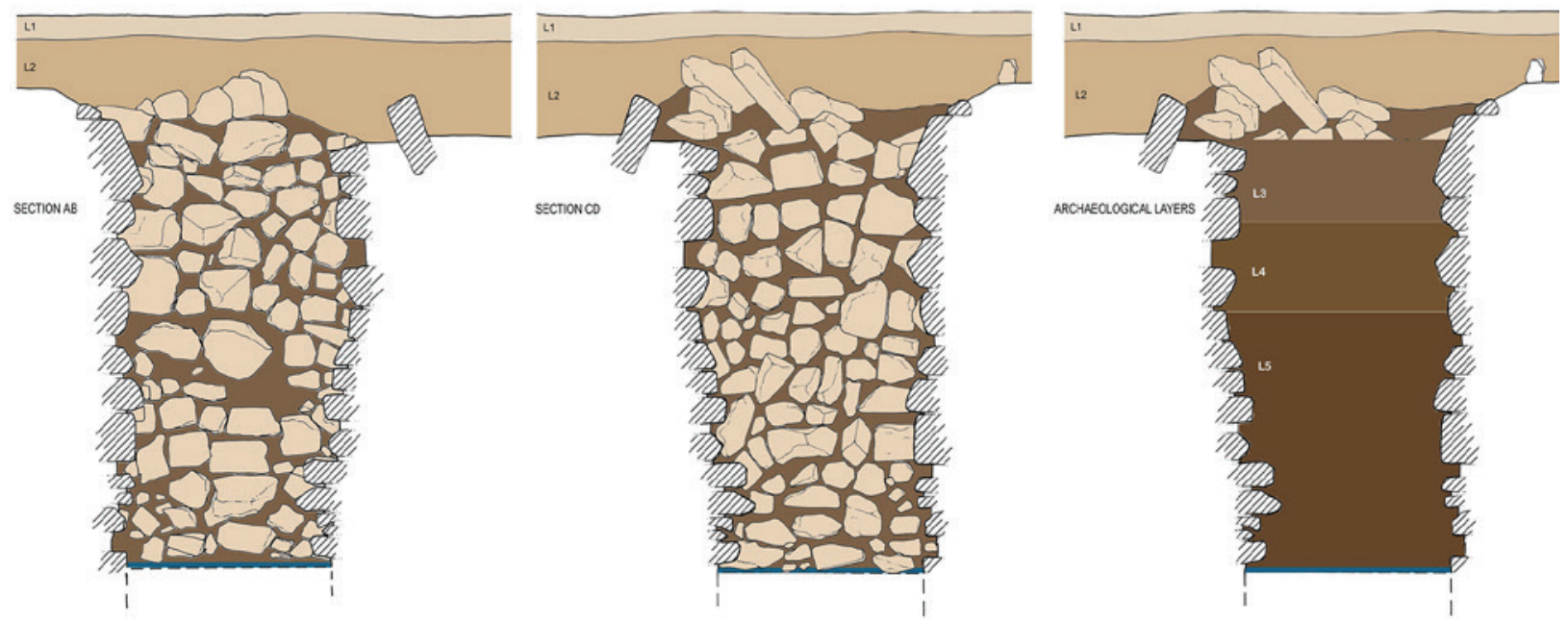

Figura 3 - Poço. Planta, alçados e corte estratigráfico (lev. J. Gonçalves). 

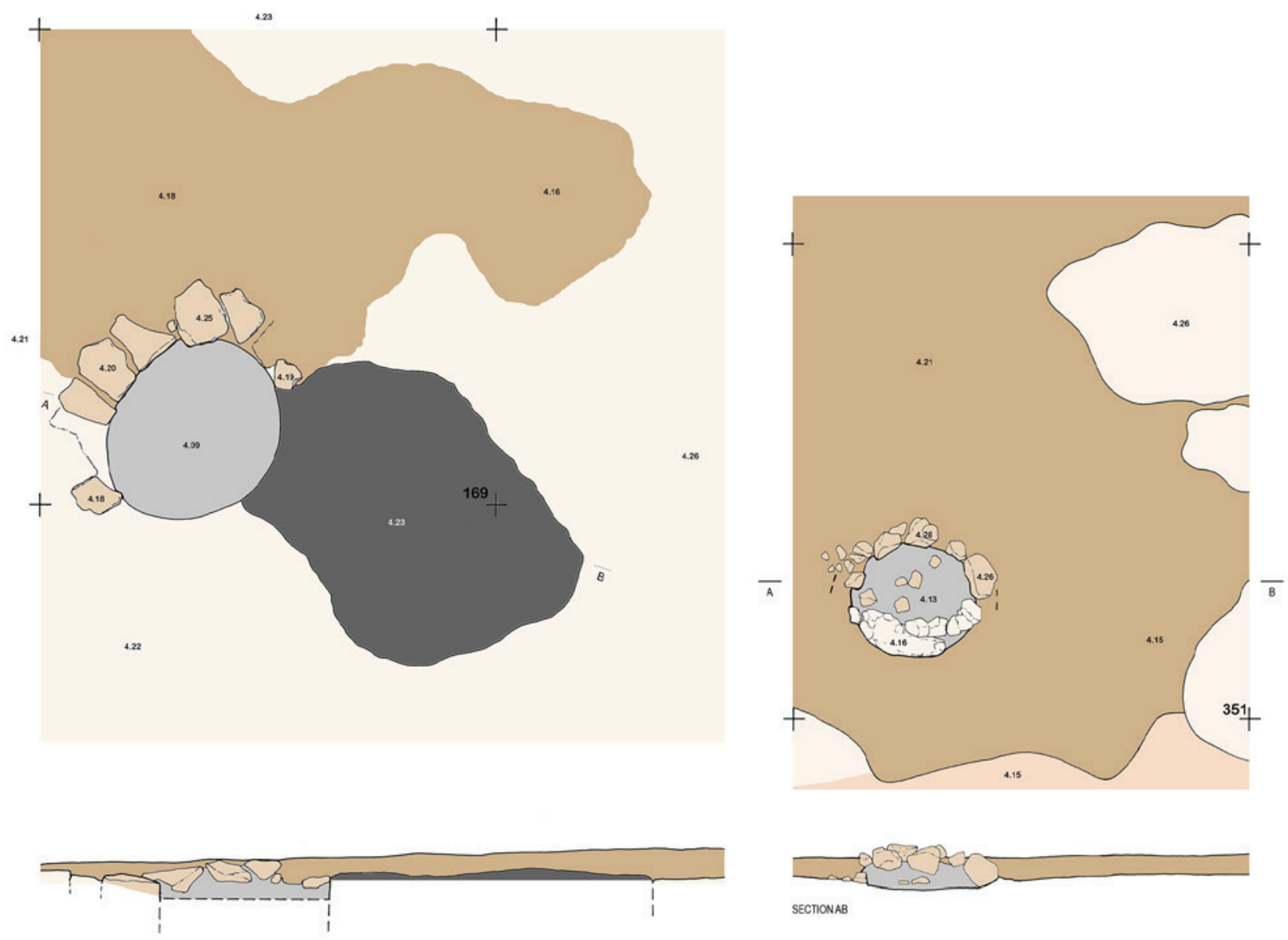

SECTION AB
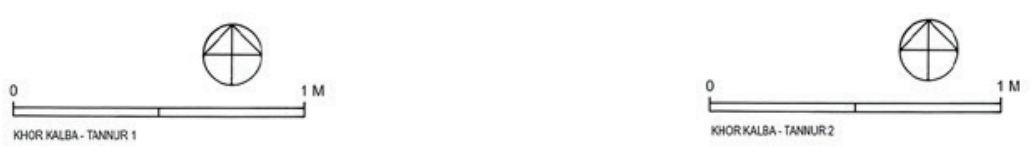

Figura 4 - Dois fornos domésticos de Quelba/Khol Kalba. Plantas e cortes (lev. J. Gonçalves). 


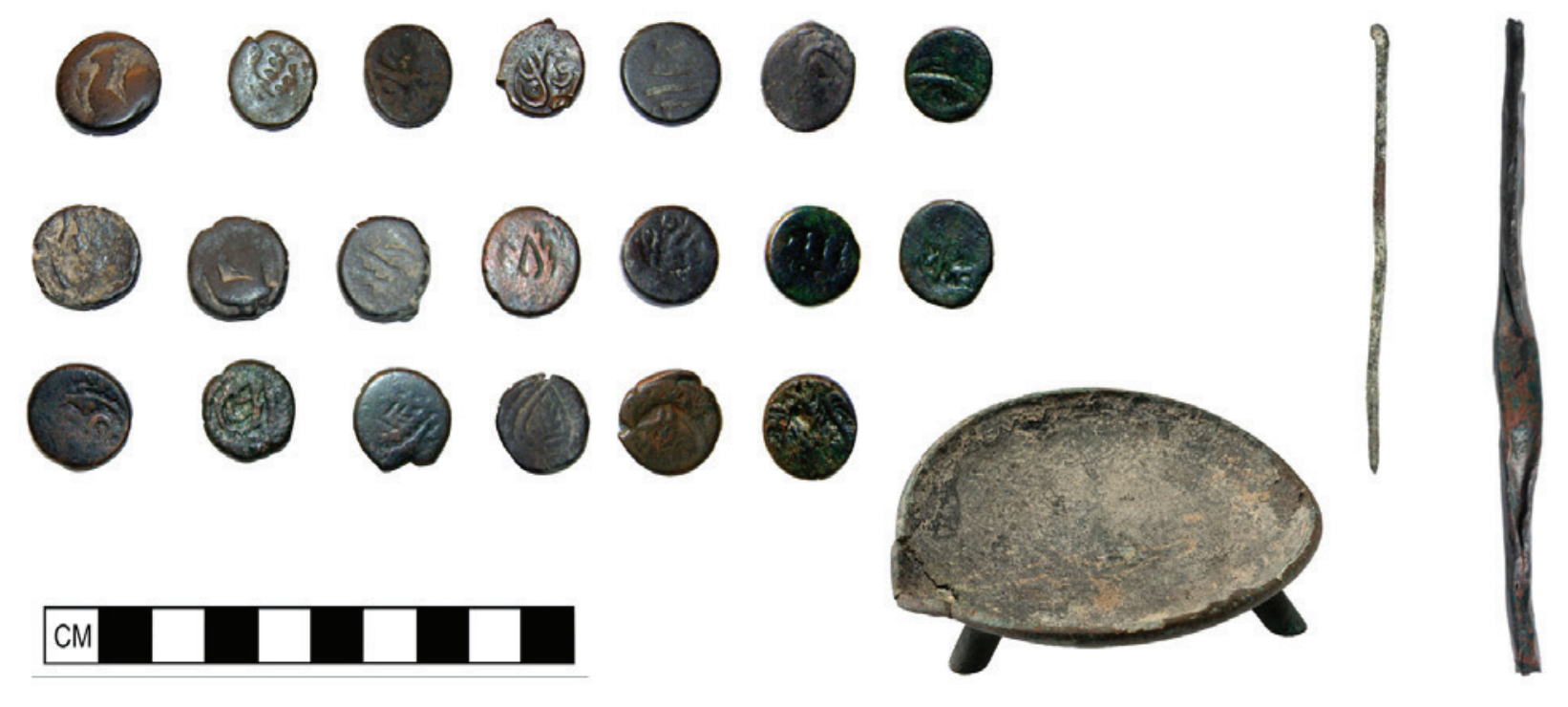

Figura 5 - Numismas safávidas e outros artefactos metálicos (queimador, alfinete e frag. de espeto) (fotos J. P. Ruas).
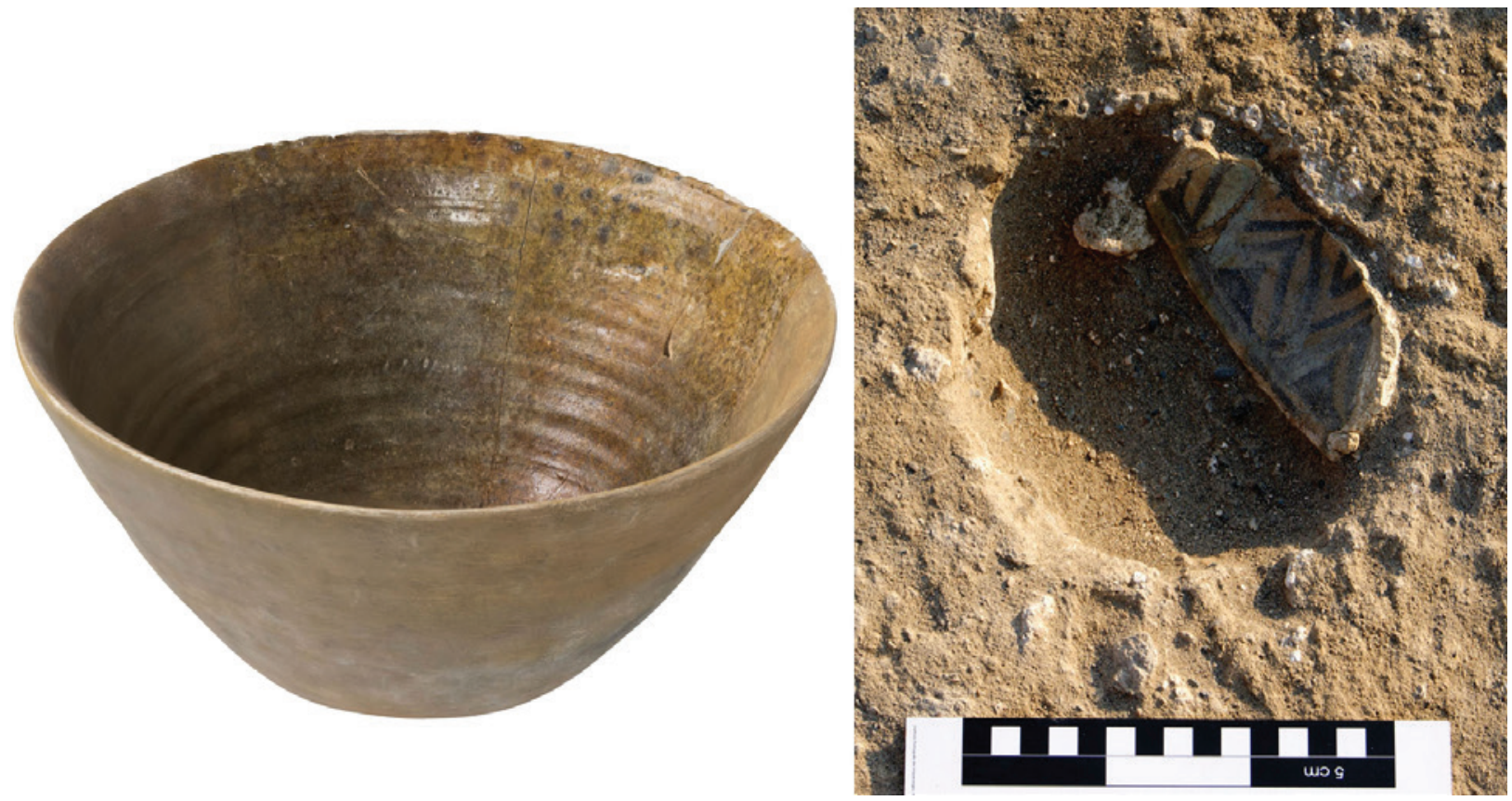

Figura 6 - Grande taça do tipo cerâmica de Bahlā e fragmento de taça de cerâmica com pintura sob vidrado, em buraco de poste (fotos: J. P. Ruas 2019 e M. V. Gomes 2018). 

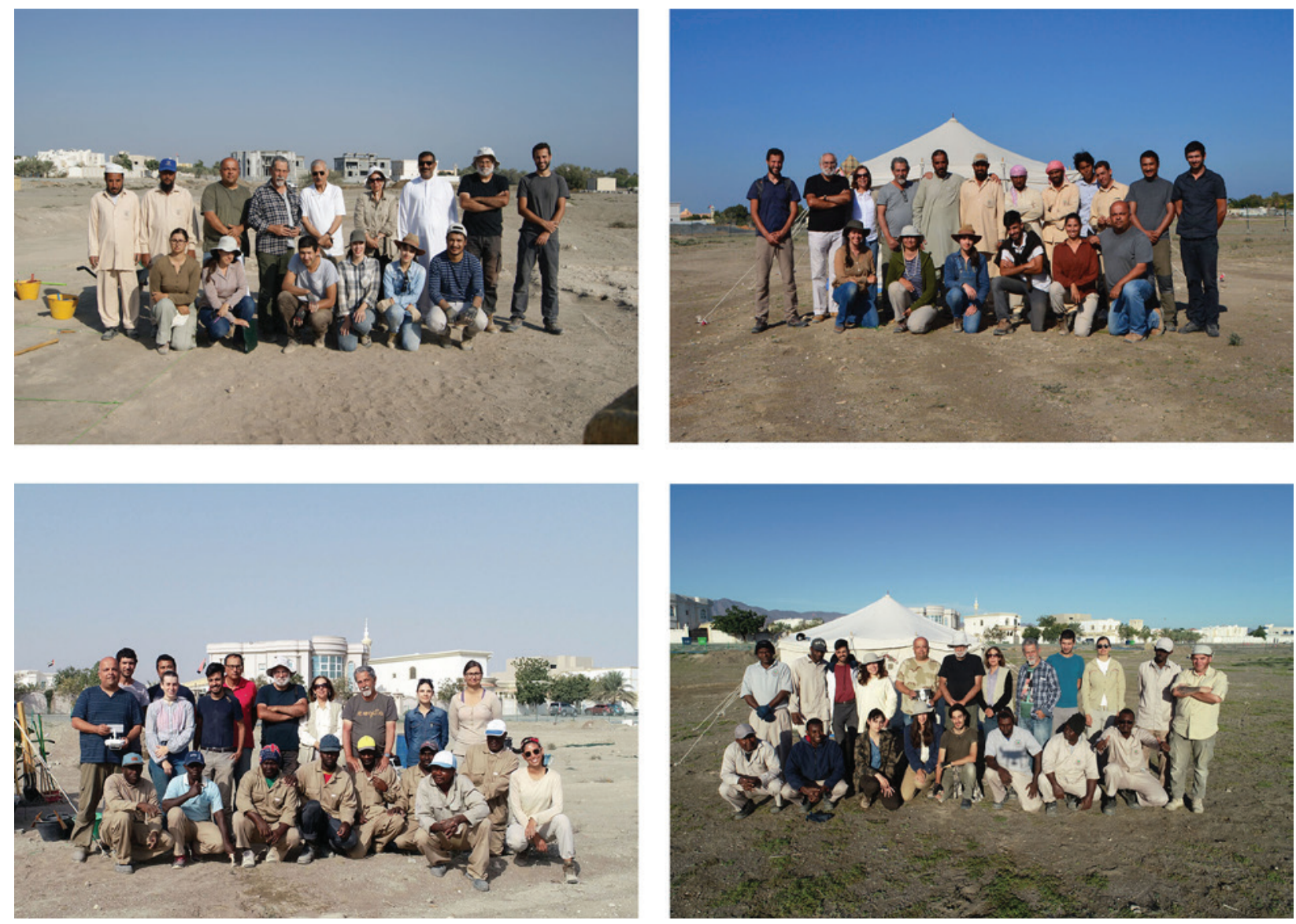

Figura 7 - Fotos das equipas de 2017 a 2020 (fotos M. N. Villanueva e K. Kamyab).

\begin{tabular}{lcccccc}
\hline Cerâmicas vidradas de cor castanha clara & 2017 & 2018 & 2019 & 2020 & Total & $\%$ \\
\hline Cerâmicas vidradas de cor castanha escura ou verde & 75 & 66 & 55 & 7 & 203 & 3,26 \\
\hline Cerâmicas com pintura sob vidrado & 1 & 57 & 10 & 9 & 77 & 1,24 \\
\hline Cerâmica fina incisa ou impressa & 283 & 179 & 168 & 51 & 681 & 10,93 \\
\hline Cerâmicas de pastas escuras & 777 & 964 & 939 & 196 & 2876 & 46,14 \\
\hline Cerâmicas de pastas vermelhas & 277 & 202 & 218 & 35 & 732 & 11,75 \\
\hline Total & 430 & 729 & 382 & 122 & 1663 & 26,68 \\
\hline
\end{tabular}

Quadro I - Fragmentos das principais classes de cerâmicas, pertencentes a recipientes, exumados na Camada 2 (sécs XVIXVII) de Quelba/Khor Kalba. 


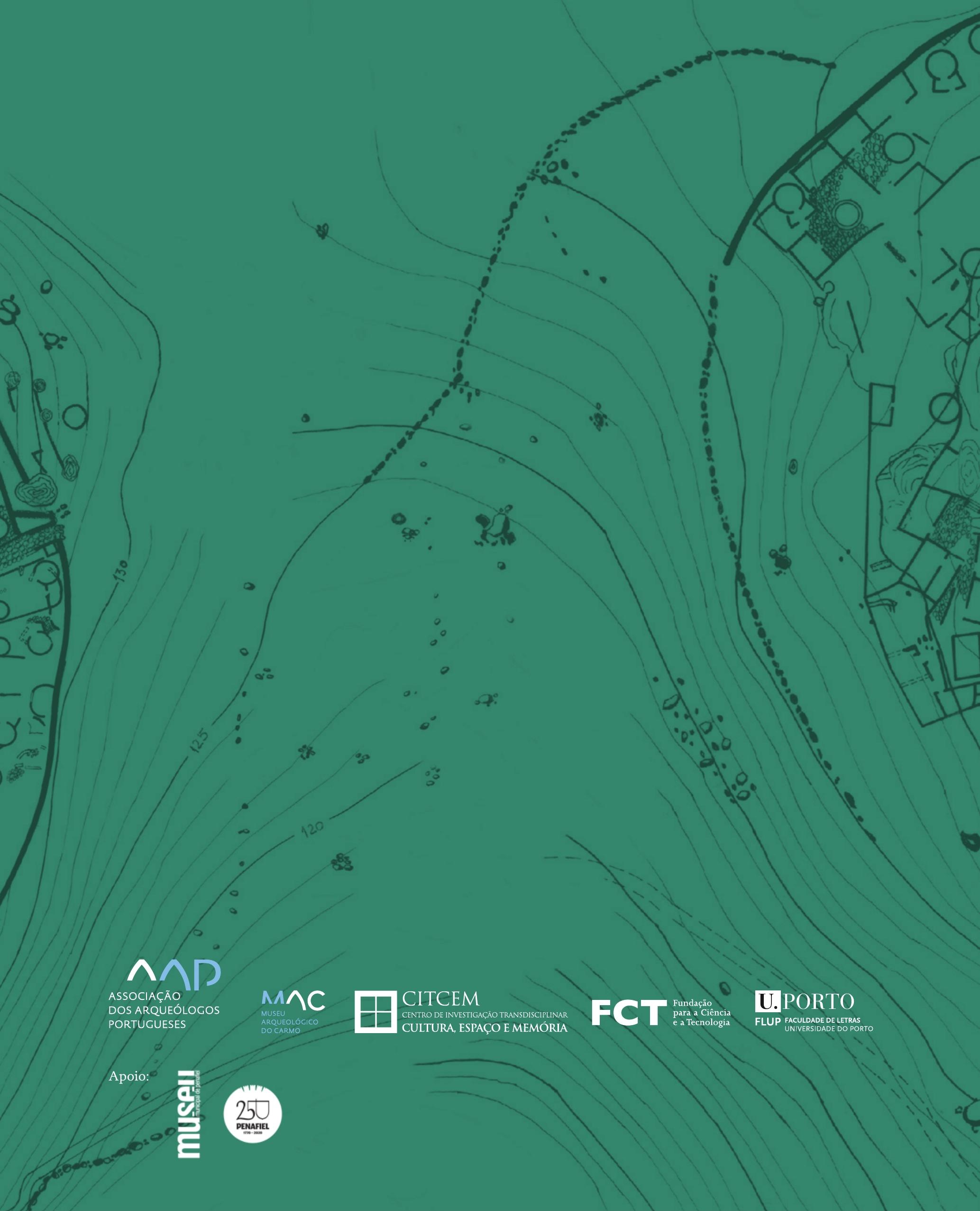

